This item was submitted to Loughborough's Research Repository by the author.

Items in Figshare are protected by copyright, with all rights reserved, unless otherwise indicated.

\title{
An enterprise architecture framework for electronic requirements information management
}

\section{PLEASE CITE THE PUBLISHED VERSION}

http://dx.doi.org/10.1016/j.ijinfomgt.2017.04.005

\section{PUBLISHER}

(C) Elsevier

VERSION

AM (Accepted Manuscript)

\section{PUBLISHER STATEMENT}

This work is made available according to the conditions of the Creative Commons Attribution-NonCommercialNoDerivatives 4.0 International (CC BY-NC-ND 4.0) licence. Full details of this licence are available at: https://creativecommons.org/licenses/by-nc-nd/4.0/

\section{LICENCE}

CC BY-NC-ND 4.0

\section{REPOSITORY RECORD}

Jallow, Abdou Karim, Peter Demian, Chimay J. Anumba, and Andrew N. Baldwin. 2017. "An Enterprise Architecture Framework for Electronic Requirements Information Management”. Loughborough University. https://hdl.handle.net/2134/25856. 


\title{
An Enterprise Architecture Framework for Electronic Requirements Information Management
}

\begin{abstract}
Managing information about client requirements effectively can contribute to improve the quality of built facilities, and their related services. However, the process has been challenging to construction project management often resulting in failed projects. This necessitates an overwhelming need for a better approach. This paper presents a novel enterprise architecture framework for managing information about client requirements across all phases of a construction project and through-life of a built facility. The Integrated electronic Requirements Information Management Framework (eRIM) defines an informationcentric, and process and service-oriented enterprise architecture approach to requirements management. It also describes how Information and Communication Technology (ICT) / Information Systems (IS) can support this information management. In developing the framework, findings from three case study projects were collated through observations, a questionnaire and interviews of construction practitioners. It is concluded that when implemented and incorporated in the management of construction projects, the eRIM architecture framework can potentially contribute towards improved and more efficient and effective management of client requirements across all stages of a project. Further work is outlined to operationalize the framework.
\end{abstract}

Key words: construction project, enterprise architecture, framework, information, requirements management

\section{Introduction}

This research recognizes that client requirements management begins during the initiation and briefing stage of a project. However, the emphasis of the proposed framework covers the subsequent stages after the brief/program is produced, including design, construction and through-life of a building. The process of managing information about client requirements in construction projects is challenging. In particular managing the information across the various lifecycle phases, and coordination and control of the requirements changes. However, it is a catalyst to successful completion of projects and contributes towards project evaluation and post-project reviews. Client requirements information is a vital construction project resource needed at each project phase and through-life of a facility. Client requirements information is initially produced as a program document (or in UK, the client 'brief') which is generated following programming, a process to establish and record client needs, wishes and expectations for a building leading to statements of architectural problem and the requirements to be met (Duerk, 1993; Pena and Parshall, 2001). Programming is often regarded as a continuous process thus the program document needs to be flexible and dynamic to incorporate emerging requirements and changes.

Consideration of requirements information is commonly concentrated at the early phases of construction projects and becomes disjoint in later phases. Once the design begins and progresses, these requirements are left aside and the design is used subsequently to interpret client wishes. Similar observations have been made by Kiviniemi et al. (2004). Managing client requirements including communication to all parties to the construction process is not easy because of the large volume of information that comprises the requirements as well as inputs from the many stakeholders involved in the process (Charoenngam et al., 2003). Generally, the voluminous information is paper-based and often difficult to manage requiring 
Jallow et al 2017. "An enterprise architecture framework for electronic requirements information management.” International Journal of Information Management, 37(5), 455-472.

the need for electronic information exchange, with ICT gradually replacing paper (Wong and Lam, 2011). The information also needs to be distributed to all project teams who require it for implementation of their individual tasks, and is often shared amongst various applications used at each phase of a construction project. This is emphasized by Aziz, Anumba and Law (2006) who state that project teams require ondemand access to information. However, project managers have a greater inclination to communicate information verbally than either visually or in writing (Laufer, Shapira and Telem, 2008). This hinders efficient and effective communication and information management in dynamic project environments. Consequently, it necessitates development and implementation of appropriate project information management systems.

The findings reported in this paper and the associated framework are part of an on-going effort to develop a better approach to managing client requirements information management with a support information system for construction projects taking a lifecycle view (Jallow et al., 2008; Jallow et al., 2014). The integrated framework (electronic Requirements Information Management - eRIM) is formulated for managing information relating to client requirements from when these requirements are first elicited in the program document through to the decommissioning and/or disposal of the facility. This framework specifies a central storage mechanism for collaborative and distributive access by all stakeholders and facilitates the management of changes. The aim of eRIM is to enable construction organizations to improve on the provision of quality facilities through better management of requirements information. The specific objectives of the Framework are: (i) to define a structured approach for a web-based centralized repository that can facilitate collaborative and distributed access to the client requirements; (ii) to define a mechanism for dependency checking between requirements; crucial for impact analysis, and cost and time assessment; (iii) to improve information exchange and sharing between all stakeholders, and interoperability between applications use for requirements management; (iv) to enhance the process of managing changes to requirements information. Specifically, the central focus of this paper is on the development of the eRIM framework and its constituent components, with implementation briefly introduced.

\section{Related Work}

eRIM research is at the intersection of three domains: the concept of requirements management, models which operationalize these models and enterprise architecture (EA), which defines the underlying mechanism to implement an enterprise-wide information management system to support requirements management. Therefore, a review of requirements research is presented to understand the current state-ofart of requirements management and efforts for its improvement. Similarly, review of EA was conducted to understand its implications, and explore links between the business and information technology (IT) dimensions for managing information about client requirements. As a result, the research requires describing and representing the enterprise structure of managing the information about the requirements from both a business and IT perspectives. Conceptualizing this will help identify the components necessary to illustrate the interactions and collaborations between them. Because of the need for collaboration and interaction between all the components, the research also needs to comprehend how to formulate rules, and standardize the application, implementation and execution of the EA. A brief description on the development of a software prototype based on the Framework is presented. However, the full detail of the system development is beyond the scope of this paper.

\subsection{Basic concept of requirements management}

Requirements management as a discipline has its origin traced from the software/systems engineering industry where it has been applied intensively and extended to other industries (Green et al., 2004). The discipline is concerned with gathering requirements from clients, organizing and analyzing this information, and managing the processes of reviewing and changing the information as well as the documents in which it is contained (Schmidt and Souza, 2007). In Architecture, Engineering \& 
Jallow et al 2017. "An enterprise architecture framework for electronic requirements information management.” International Journal of Information Management, 37(5), 455-472.

Construction and Facilities Management (AEC/FM), these processes are spread across the entire lifecycle of a construction project and the resulting facility.

At each phase of a project, activities are centered on satisfying the client requirements during which changes in requirements may occur. This involves managing the requirement attributes, tracing changes, and analyzing the impact of those changes on time, schedule, value, benefits and other stakeholder requirements. No known system exists that helps to integrate requirements management across all lifecycle phases of a construction project. Very few requirements management approaches define integration into later phases after briefing. Most of those frameworks complement the design process only. Previous research has considered the development of some models that can facilitate the process.

\subsection{Requirements management models}

The client requirements processing model (CRPM) was developed to help in the definition of client requirements and the incorporation of the different perspectives represented by the client body, and assist in the systematic mapping or translation of the requirements from the business terminology ("voice of the client") that clients are likely to use into design terms ("voice of the designer"). Its aim is also to ensure requirements are presented in a solution-neutral format (Kamara, Anumba and Evbuomwan, 2002). Kamara and Anumba (2000) argue that "it is necessary that 'processing' be done before conceptual design.” CRPM has three main stages for the processing of requirements: (i) defining client requirements, (ii) analyzing client requirements and (iii) translating client requirements.

During all these stages, managing the elicited requirements is of great importance. However, it is apparent that the CRPM only feeds into the design phase of a construction project but does not apply throughout the lifecycle phases of a project. The CRPM helps capture client requirements and facilitates design development. It serves as a link between project conception and design. In other words, "CRPM serves as the interface between the client's business needs and design requirements" (Kamara, Anumba and Evbuomwan, 2002). Design solutions are subsequently used to facilitate the construction of the facility as well as to aid material procurement process. The original requirements documents become redundant in the later phases of a construction project having been substituted by the schematic and detailed design. However, this research argues that the requirements management process should be continued throughout the phases of a construction project and building life, and not just to aid design.

Managing requirements along all phases of a construction project does not only help different teams perform their work efficiently but can contribute to elimination of waste in design and construction. This research argues that construction defects can be reduced immensely with lifecycle management of requirements information. A similar observation was made by Baldwin et al., (2007) that waste can be eliminated in both design and construction process by ensuring the timely delivery of design information and process, and information modeling can facilitate that process.

Kamara, Anumba and Evbuomwan (2000) note that different media such as drawings, sketches, text and other forms have been used to manage and communicate requirements. This is emphasized by Fiksel and Dunkle (1992) who point out that "there are a variety of forms in which requirements can be represented, including documents and drawings." Computational tools have emerged that help to manage the different media. In the construction industry, most of these applications are general purpose computer applications such as word processors, spreadsheets and databases in some cases with few specialized applications. There are many disadvantages associated with general purpose applications, and there is a recognized need for more advanced tools. To manipulate changeable requirements for architectural design, computational requirements management and engineering strategies need to evolve with set of procedures (Ozkaya and Akin, 2007). To address this problem, the Computational Hybrid Assistance for Requirements Management (CHARM) framework was developed. CHARM establishes a process 
Jallow et al 2017. "An enterprise architecture framework for electronic requirements information management.” International Journal of Information Management, 37(5), 455-472.

whereby a designer/architect needs to be aware of the requirements information of a given solution, or track emerging data by interacting with the computational system (Ozkaya and Akin, 2007).

Kiviniemi et al. (2004) and Kiviniemi (2005) working on requirements management present a framework focusing on the requirements model and its interconnection to the architectural design model by creating a link between "requirements objects" in the "requirements model", and objects in design, production, and maintenance models. These links are relevant for traceability purposes; however, the links should be categorized to help define the degree of dependency or relationship from one requirement to another. Consequently, this research adopts the philosophy of these links as a point of departure to facilitate defining their categories and how they can be applied across the lifecycle phases. The paper also adapts and extends the capabilities and utilization of the links to enhance the checking for dependencies between requirements during changes, which is crucial for impact analysis on budget, schedule and other defined factors such as value and benefits. Meziane and Rezgui (2004) present a document management methodology for the management and sharing of documents in the construction domain. It aims to facilitate the identification of documents and management of the updating process of those documents, and to deal with heterogeneous and large database of documents.

All these different models and frameworks discussed have the potential to facilitate the requirement management processes within the construction industry. However, the extent to which this is done is limited compared to the need for a lifecycle requirements management support for construction projects.

Many specialized commercial software tools exist that claim to be able to provide requirements management. According to Oduguwa (2006), the three industry leaders are recognized as DOORS from Telelogic, Slate (part of Teamcenter) now owned by Siemens (Siemens, 2011) and Calibre-RM from Borland which provide common support for requirements management. However, they are not able to provide detailed impact analysis when a design requirement is changed. Halbleib (2004) and Kamara, Anumba and Evbuomwan (2002) also identify similar commercial requirements management tools. An evaluation of some of these tools was also reported by Tvete (1999) to enable selection of one to be used for their purpose. These software tools are generic and have been developed for use across different industry sectors. However, none have become adopted as standard for the construction industry. For example, product lifecycle management (PLM) systems support and automate the product development process from conceptualization for a product and ending with the end-of-life. They provide a single source of all the product information, and facilitate integration of people, processes and systems (Pearlson and Saunders, 2012). PLM is used heavily in manufacturing for example, but has, no known adoption in the construction industry, which is dominated by small and medium-sized enterprises (SMEs). Such systems are mostly oriented towards large-sized firms, which pose a challenge for small and mid-sized enterprises (Soto-Acosta, Placer-Maruri and Perez-Gonzalez, 2016).

Other systems were developed as research outputs. Notably, EGRET, developed by Sinha, Sengupta and Chandra. (2006), is a collaborative requirements management tool aimed at supporting the requirements communication and management across distributed software development teams. This was specific to the software industry and might not be entirely applicable to construction. However, the concept addresses similar problems and challenges to those of the AEC/FM industry. It is crucial that in order to support and enable multidisciplinary teams to work collaboratively, requirements should be structured, processed and presented in a format that will facilitate that process (Kamara, Anumba and Evbuomwan, 2002; Kiviniemi, 2005). Therefore, the study reported in this paper emphasizes that a clearly defined process has to be instituted before applying a tool for managing requirements information.

Enterprise systems such as Document Management Systems (DMS) and Enterprise Content Management (ECM) are used to help management documents and information in organizations, but they do not support the features required for managing requirements. ECM are tools, processes and strategies used to manage organizations' information. This can include both structured and unstructured documents - including hard 
Jallow et al 2017. "An enterprise architecture framework for electronic requirements information management.” International Journal of Information Management, 37(5), 455-472.

copy, web content, images, email, databases (Hullavarad, O’Hare, \& Roy, 2015; Alalwan, \& Weistroffer, 2012). Both DMS and ECM are systems that help businesses to organize, manage and distribute content such as documents, images, product information, emails, and web pages. They facilitate storage, access collaboration on the content between participants. While both DMS and ECM heavily focus on management of the files or documents themselves and unstructured information, ECM goes beyond the idea of a file as an object to be managed and addresses other technical and organizational challenges related to managing content (Haug, 2012). In the construction industry, DMS and ECM have been used in the development of project extranets, which make use of a central shared storage drive and are increasingly being used and relied upon widely by construction teams for information exchange and collaboration (Wilkinson, 2005; Erdogan et al., 2008; Moses, El-Hamalawi, \& Hassan, 2008). They facilitate the access of project documents but are temporary repositories for the duration of projects and usually do not also adequately provide process management (i.e., coordination of information flow between humans and systems and across lifecycle phases of a building). They are document-centric rather than data/information-centric (Chassiakos \& Sakellaropoulos, 2008). This means they help to manage the documents themselves rather than the project information. Although these types of systems have huge benefits, they are limited in providing the functionalities required in managing requirements information, in particular providing change management functions such as dependency checking and coordination of the process. It is clear that ECM provides a centralized repository for data storage and includes features for control and information analyzes (Maican and Lixandroiu, 2016). However in comparison to process management systems, Bock also emphasize that ECM systems are hugely file-oriented whereas BPM systems are database-driven (Schooff, 2013). eRIM is innovative in that it is information-centric rather than document-centric as in DMS/ECM. It is also process-and service-oriented in exchanging information between different systems, and specifies the mechanism for impact analysis through dependency checking, and automation of the change management process.

Little research has advanced in requirements management in construction, and no known development has been reported in the use of specialized software for requirements in construction. Even where a system exists, an underlying framework must be available to specify how that system should be used, factoring in the lifecycle phases \& processes, information structure, information flow within the organization, and the process for managing changes. Maican and Lixandroiu (2016) also underline that a BPM application can be implemented to handle other data and information flows and not only the document flow within an organization as with DMS. This necessitates the need for process and information-centric frameworks and systems.

The need for a model or framework for requirements management has been emphasized in recent studies (Yu, Shen, \& Chan, 2010; Yu and Shen, 2013; Jallow et al., 2014). A preliminary framework was proposed by $\mathrm{Yu}$, Shen, \& Chan (2010), which focused to show the processes involved in requirements management. An initial framework was also presented by (Jallow et al., 2010). Similarly, Alshubbak et al. (2015) recognizing the importance of identifying owner's needs in all phases of a project, which are not always adequately considered, developed a model that allows for the identification of the owner's needs in all phases of the building life cycle. These owner's needs are the client requirements information.

\subsection{Enterprise Architecture (EA)}

"Enterprise architecture" has been defined in a variety of ways depending on organizational and application aspects. Ross, Weill and Robertson (2006) define EA from the perspective of business processes and IT infrastructure as an organizing logic that reflects the requirements for integration and standardization of a company's operating model. Pearlson and Saunders (2012) indicate that organizations use EA for the organizing logic, often specifying how information technologies will support business processes. EA recognizes and specifies the main organizational processes, and defines how they will work together; map-out how the IT systems will support the processes, the standard technical 
Jallow et al 2017. "An enterprise architecture framework for electronic requirements information management.” International Journal of Information Management, 37(5), 455-472.

capabilities and activities for all parts of the enterprise (ibid). Chen, Doumeingts and Vernadat (2008) underscore the need for EA to be structured in a manner that supports reasoning about the three components of the system: structure, properties and behavior. Similarly, Ross, Weill and Robertson (2006) observe that EA include common elements:

i. core business processes: those enterprise processes that provide core capabilities needed to execute the operating model to create products and services,

ii. Shared data: data required to drive the execution of the core processes. This data may be shared across functional units of the company,

iii. Linking and automation technologies: these include software, hardware, and networks (including) internet technologies to facilitate integration and interoperability, which enables access to shared data between all stakeholders, and

iv. Key customers: these are the customer groups who will be served by the EA when implemented into an IT infrastructure and system.

Organization should use a clear architectural design approach based on principles, standards, and beliefs on how the architecture should function (ibid). There are several EA frameworks that are used a models and standards for designing architectures. Two of the major frameworks are: The Zachman Framework and TOGAF (The Open Group Architecture Framework).

- The Zachman Framework: defines architectural needs by providing a broad view that helps guide the analysis of the detailed view. Its perspectives range from the company's scope to its critical models and, finally, to very detailed representations of the data, programs, networks, security, and so on. Zachman framework uses the conceptual business model, the logical system model, and the physical technical model. The framework is depicted as a bounded $6 \times 6$ "matrix" with the Communication Interrogatives as Columns and the Reification Transformations as Rows; the classifications are represented by the Cells, that is, the intersection between the Interrogatives and the Transformations. The rows specify the: scope, business model, system model, technology model, components and working system. The columns specify: who, when, why, what, how and where (Zachman International, 2008, Minoli, 2008; Pearlson and Saunders, 2012; Buchanan and Gibb, 2007).

- TOGAF: as an architectural framework, TOGAF is used as an Architecture Development Method (ADM), which is used to define business requirements and developing an architecture that meets those requirements, utilizing the elements of TOGAF and other architectural assets available to the organization (The Open Group, 2006). It specifies a set of methods and tools for developing wide-ranging IT architectures. It enables the design, evaluation, and implementation of the right architecture for organizations based on open systems solutions. TOGAF supports the design of all types of architecture subsets: a business architecture, application architecture, data architecture and technology (ibid; Minoli, 2008; Pearlson and Saunders, 2012; Buchanan and Gibb, 2007).

\section{Research Methodology}

This work is part of a broader research effort aimed at specifying a better approach to managing client requirements information in construction. Initially, an empirical study on the complexity of requirements management in construction projects was conducted through a case study (Jallow et al., 2014). The study recommended that effective management of client requirements requires a better approach to manage the complexities, and eventually proposed an integrated framework (ibid). The case study of three projects managed by an engineering project management organization was conducted during a two year period. The main reason for selecting the case study approach was to enable an in-depth examination and analysis of the process of managing client requirements as applied in the context of construction projects. This process included an understanding of how requirements are gathered, stored, accessed, exchanged and communicated between stakeholders and interpreted in the later stages of a project. The case studies also 
Jallow et al 2017. "An enterprise architecture framework for electronic requirements information management.” International Journal of Information Management, 37(5), 455-472.

demonstrated how changes to client requirements are requested and handled through the approval process and how the information generated from it is managed. This approach was appropriate to help formulate conceptual theory for understanding the state-of-the-art of requirements information management and exchange between stakeholders.

A critical component of the methodology was of an assessment of the requirements information management business process and interactions between stakeholders of construction projects. This assessment also included the tools (i.e., program documents, Request for Change forms, computers and design documents amongst others) used to accomplish requirements management. These helped to identify the reengineering needs for effective and efficient requirements information management and exchange, and desired future models and tools. The research also reviewed literature on general requirements management in construction and other industry sectors (such as manufacturing and software engineering) in order to understand the similarities and to learn and adapt techniques where necessary. The review also identified currently available technologies that could be adopted to enable design and implementation of a framework and associated tools. The need for the framework and its constituent elements emerged from the analysis of the case studies, which was analyzed using thematic analysis (Jallow et al, 2014). The requisite for the framework which emerged from the case studies included: an approach to managing client requirements at each phase of a project (i.e. throughout the lifecycle of a building or facility), and not only at the early stages; a centralized storage system (i.e., requirements data hub); the effective and efficient management of the requirements change process. The development of such an enterprise architecture framework to enhance lifecycle requirements information management in construction is presented in the next section of this paper.

Evaluation of the framework by assessing its applicability in managing information about client requirements was conducted. A summative approach was considered for use in the evaluation of the Framework and prototype. According to Clarke (1999) and Gray (2009), summative evaluation is used to establish how effective a process, system, project or program is and to provide judgement on it.

\section{The Enterprise Architecture Framework (eRIM)}

\subsection{Introduction}

The enterprise architecture framework for electronic Requirements Information Management (eRIM) defines a holistic approach to lifecycle client requirements information management. The framework incorporates the importance of: managing client requirements information at each phase of a project and throughout the life of a building or facility; a centralized storage system; easy access to details of the requirements for all the project stakeholders; and effective coordination and control of the requirements change process. It complements related work (Jallow et al, 2014) which highlights the complexity of managing information about client requirements, and proposes an integrated framework to facilitate a better approach. The aim of eRIM is to help construction organizations to improve on the provision of quality facilities through better management of requirements information.

eRIM provides a defined and controlled requirements management process that registers client requirements from program document stage, through design and construction and all through the life of the facility. It ensures that details of client requirements are available at all times; provides a history of previous changes to requirements and enables the project manager to manage change effectively through a defined and controlled change management process. eRIM has been developed from an informationcentric perspective with the concept of providing an on-going view of clients' requirements. It places emphasis on collaborative working and interoperability, thus enabling information sharing and exchange between humans and systems (both homogeneous and heterogeneous), providing collaborative and distributed access to requirements information over a centralized repository (data hub) with lifecycle approach. 
Jallow et al 2017. "An enterprise architecture framework for electronic requirements information management.” International Journal of Information Management, 37(5), 455-472.

Two types of requirements are defined for the purpose of discussing the Framework. These are primary requirements and secondary requirements. From a hierarchical point-of-view, the high-level initial client requirements stated in a brief (i.e., program) are regarded as primary requirements. Those are the composite, and the secondary requirements are sub-level components of the primary requirements. Room datasheets for example, produced at the design phase are regarded as secondary requirements. Requirements vary in precision and detail as projects progress; therefore, distinguishing requirements into these two categories was relevant.

\subsection{Overview of eRIM}

eRIM specifies a structured and controlled requirements information management process that registers client requirements after the production of the brief; throughout design and construction, and all through the life of the building. It ensures that details of client requirements are available at all times; enables the project manager to manage requirement changes effectively through a coordinated and controlled change management process and provides a history of previous changes to requirements. eRIM has been developed from an information-centric, process and service-oriented perspective with the concept of providing an ongoing view of client requirements. It places emphasis on collaborative working, information and process management, management of changes, integration and interoperability, thus enabling information sharing and exchange between people and systems (both homogeneous and heterogeneous systems); providing shared and collaborative access to requirements information over a centralized repository which remains up-to-date through-life, which is critical for decision-making. Similar features have been discussed by Arayici, Ahmed and Aouad (2006) as components of a proposed integrated project information system for use throughout the whole life-cycle of a project. Maican and Lixandroiu (2016) who included a BPM in their system architecture regarding ECM use also indicate the need for organizations to use integrated enterprise systems as they make work easier, contribute to faster decision-making, based on accurate data/information thus contributing to efficient management. Information is important to any organization. Abdul Karim and Hussein (2008) similarly emphasize this view that organizations can enhance efficiency, improve decision-making and gain competitive advantage with good quality information.

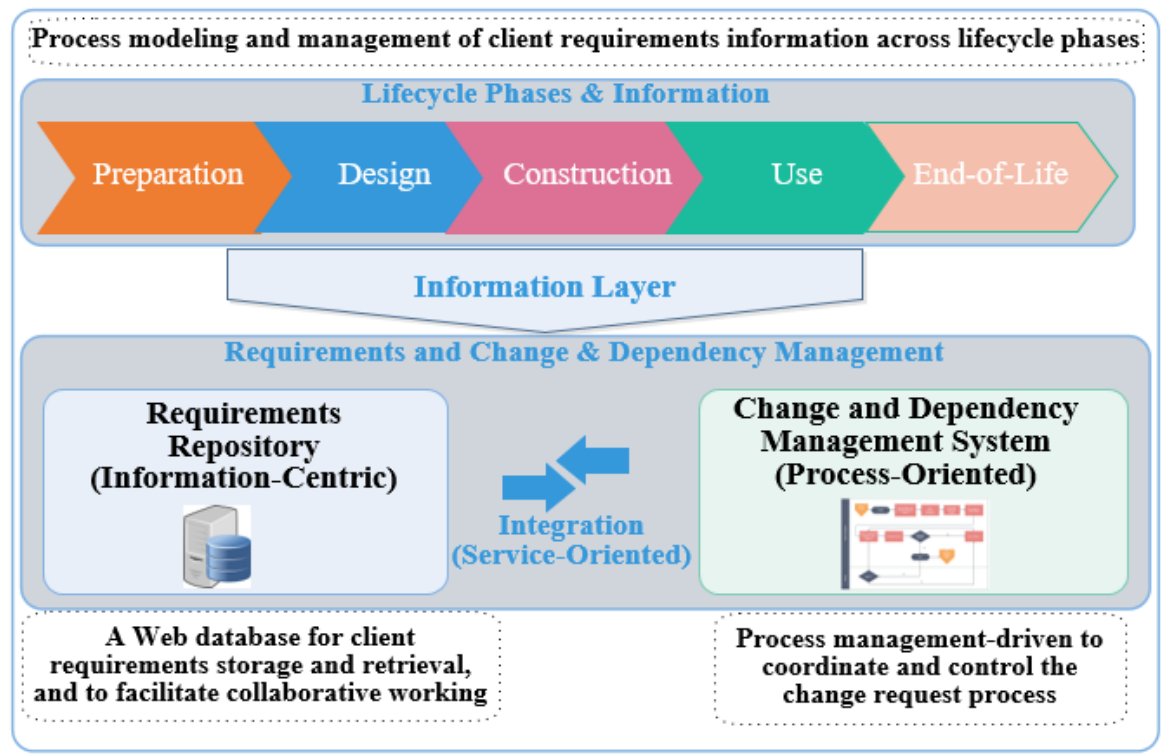

Figure 1: High-level view of eRIM Framework 
Jallow et al 2017. "An enterprise architecture framework for electronic requirements information management.” International Journal of Information Management, 37(5), 455-472.

A high-level view of the eRIM framework is shown in Figure 1. It comprises: (i) a requirements repository, and (ii) a change management component which is business process management-oriented to manage the requirements change orders/requests and authorization process. The framework has a supporting scheme which defines requirements information to be identified for each of the project/facility lifecycle phases. Stakeholders and various tools use for requirements management are also highlighted. Because of the challenges of integrating different construction information management systems, the framework also defines an integration procedure based on existing technologies. The information-centric approach adopted here constitutes a paradigm shift from the traditional paper-based or document-based approach of managing client requirements to managing the content (i.e., the information itself) rather than the documents that contain the information. The process-oriented concept places emphasis and focus on coordination and control of the set of activities (i.e., the business processes) and their interrelations, which are performed when managing information about client requirements, in particular managing the changes.

Figure 2: High-level view of eRIM Framework

\subsection{Issues Relevant to the Development of eRIM}

The approach behind the design and development of the framework is based on both theory and empirical findings from the case studies. Three main issues relating to this formed the basis for the development of the framework. The rationale for the selection of these issues is as follows.

\subsubsection{Organizational Issues}

Within the construction industry, different companies, teams and expertise come together (in the form of client, contractor, sub-contractors, engineers, consultants, users, suppliers, etc.) during a construction project working to fulfill the client requirements. As a result, the venture becomes collaborative requiring all stakeholders to interact and collaborate on matters of the project. This requires meeting relevant partners, creating, indexing, and archiving documents and information in a manner accessible to all stakeholders, and client requirements are an example of such information. Consequently, the need to facilitate the management and accessibility of those requirements becomes necessary. However, each of the teams may be operating from different geographical locations, utilizing their own information management system entirely isolated from the rest of the project team and having different processes from the rest. This is particularly significant because construction (as well as the aerospace, automotive and healthcare sectors) are context-dependent and involve proprietary information (Zhao et al., 2008). Thus the need to define an approach to bring all stakeholders together in an integrated working environment becomes a necessity. Other organizational issues include social, cultural and policy factors within the different firms. The individual differences between the people involved to produce the products could affect the success of the project. The cultural differences, which means the different ways of working of the various companies could also impact the project processes. Organizational policies defining the execution processes may not be generic across all companies, which without being streamlined could be difficult to manage. All these issues have effects on how requirements information can be managed across all participating companies.

\subsubsection{Project Lifecycle Issues}

A construction project comprises different lifecycle phases (i.e., preparation, design, pre-construction, construction, use/operations and decommission). Client requirements are implemented at each of the phases. Thus, this demands managing requirements across the phases and between all stakeholders and their constituent companies or institutions. However, the degree of precision and the detail of client requirements information may vary from one phase to another. There are also systems used at each phase for handling information used at that particular phase. Therefore, there is the need to maintain the relationship between and integrate requirements information and processes at different phases. 
Jallow et al 2017. “An enterprise architecture framework for electronic requirements information management.” International Journal of Information Management, 37(5), 455-472.

\subsubsection{Systems and Information Exchange Issues}

Generally, in construction projects, different computer systems are used in silos for managing project information. This includes requirements storage, retrieval and dissemination. Most of these systems are heterogeneous and are technically not integrated and interoperable. Information exchange between these systems can be difficult. Therefore, there is the need to define a systematic approach to make sure the systems are integrated and able to share and exchange information between them, therefore providing an interoperable platform, enabling information access and exchange across heterogeneous systems, preferably through the cloud.

In addition to the issues identified above, this research recognizes that four characteristics of organizational management (i.e., business process management, change management, information management and collaboration) are essential enablers of requirements management process due to the fact that they entail elements relevant to the management of requirements. Therefore, a comprehensive and integrated approach that embeds principles of all four characteristics described in Table 1, needs to be incorporated within the Framework to facilitate the requirements information management process as shown Figure 2.

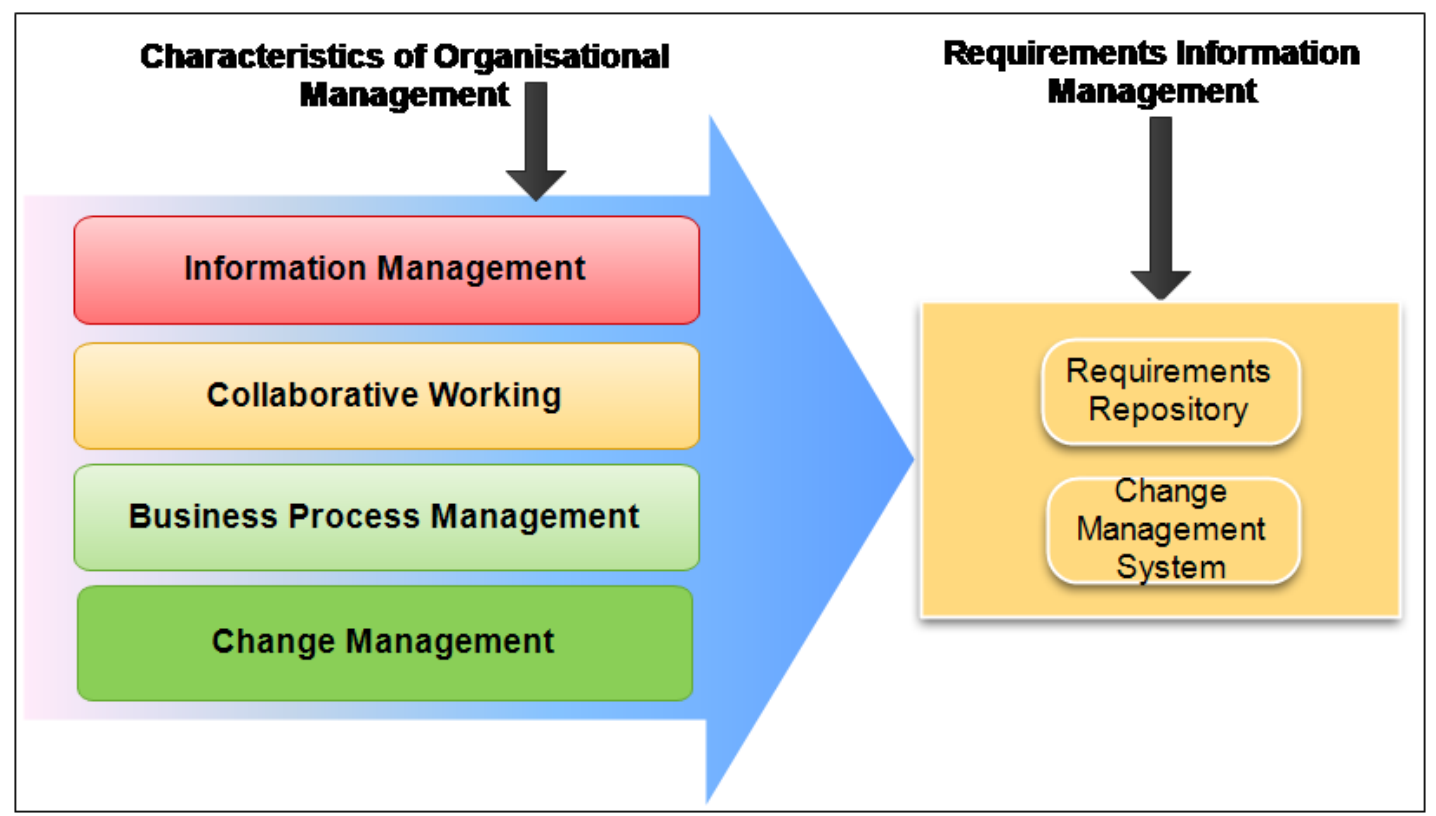

Figure 2: Four characteristics of organizational management for requirements information management

Lack of their input towards the requirements management process could potentially jeopardize successful implementation and execution of any requirements management efforts.

Table 1: Description of the Characteristics of Organizational Management

\begin{tabular}{ll}
\hline $\begin{array}{l}\text { Characteristics of Organizational } \\
\text { Management }\end{array}$ & Description \\
\hline Information Management & $\begin{array}{l}\text { Integrative activities related to information services, } \\
\text { including information creation, storage, distribution and } \\
\text { disposal. }\end{array}$ \\
\hline Collaborative Working & $\begin{array}{l}\text { Structures to support coordination, communication, } \\
\text { interaction and integration of project teams }\end{array}$ \\
\hline Business Process Management & Automated and streamlined coordination and control of \\
\hline
\end{tabular}


Jallow et al 2017. "An enterprise architecture framework for electronic requirements information management.” International Journal of Information Management, 37(5), 455-472.

\begin{tabular}{ll}
\hline & $\begin{array}{l}\text { processes, including modeling, execution monitoring, and } \\
\text { optimization }\end{array}$ \\
\hline Change Management & $\begin{array}{l}\text { Formalized set of activities that ensure that } \\
\text { product/service changes are implemented appropriately } \\
\text { includes tracking, visibility, audit trail, dependency and } \\
\text { impact analysis. }\end{array}$ \\
\hline
\end{tabular}

In developing the framework, this research considered design principles and specifications of both the Zachman and TOGAF frameworks, and selected those components that are needed to support requirements management in this industry context. These frameworks informed the research the viewpoints and artifacts/components (e.g., processes, models, data \& storage, technology, applications, participants, etc) that can be relevant to use for requirements information management, and the process to develop the framework.

\subsection{4 eRIM Development Process}

In order to develop the eRIM framework, it was initially essential to define the lifecycle phases of a building. Accordingly, two of the common models of project lifecycle phases were considered and reviewed. These are the Plan of Work by the Royal Institute of British Architects (RIBA, 2013) and the Process Protocol (Kagioglou et al., 1998). The review included determining the model that is more familiar to, and commonly used in industry. Consequently, the RIBA Plan of Work was adopted and its lifecycle phases chosen for eRIM. This decision was also supported through interviews and observations carried out during the case studies in which the RIBA Plan of Work was used. Similar observations and choice were made by Thomson et al. (2008) when adopting a project lifecycle process by indicating that consideration of various interpretations, and supported by practitioners representing each of the project teams involved across the lifecycle during a series of interviews, revealed that the Plan of Work 2013 provided the most recognizable interpretation of project lifecycle phases. Following the selection of a project lifecycle process model, it was observed carefully how the client brief was used across each project phase, and how it evolves with more detailed information in later phases. This led to the identification of the different types of requirements information and the documents in which they are held. These documents were then classified according to the lifecycle phases in which they are used. Relationships between the documents were determined relative to the requirements they held, thus mapping out dependencies between the requirements. In order to define a central storage and seamless access to the requirements information, the research reported in this paper considered these factors and specified the most appropriate mechanism.

Understanding and defining the request for change process within the general requirements management was inevitable. As a result, to support the development of eRIM, the requirements change management process as observed in the case studies was modeled. The different stakeholders and the channels used to request changes were also identified and embedded in the framework. BPMN (Business Process Model and Notation), a modeling notation (OMG, 2011) was used to model the requirements change management process from BPM (Business Process Management) perspective. The development process is graphically represented in Figure 3. It is important to note that the change management processes was specific to the case studies and generally not representative of the entire construction industry. It was used to develop the framework and as a proof-of-concept. 
Jallow et al 2017. "An enterprise architecture framework for electronic requirements information management.” International Journal of Information Management, 37(5), 455-472.

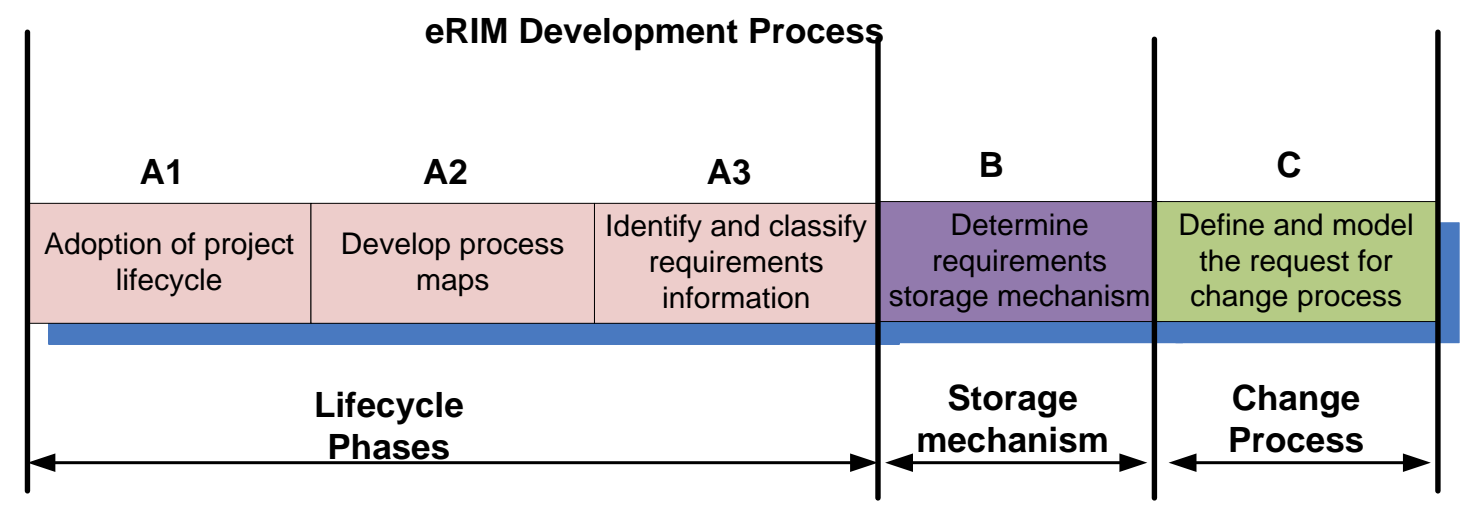

Figure 3: eRIM development process

\subsection{Components of the Framework}

This section describes the various components of the eRIM framework. The framework is informationcentric, and process and service-oriented, and comprises two main components; a requirements repository and change management process. A third component is a supporting scheme (i.e., lifecycle phases). Interaction between project stakeholders and tools use for managing requirements is also specified. The section also discussed how the components may be practically instituted and used.

\subsubsection{Lifecycle Phases}

A construction project is composed of various phases, and client requirements change in detail from one phase to another. Traditionally, these requirements are contained in a number of different paper documents and held in various locations. Client requirements must therefore be structured and represented at each project phase in different levels of detail. At the earliest phase, requirements could be represented in simple business (i.e., non-technical) language describing the business case and client needs of the project in a brief. The content and representation becomes more detailed in the later phases, for example in design specifying requirements for individual building elements, producing specifications and room datasheets. eRIM accommodates this need by recognizing project and facility lifecycle phases and types of documents at each phase. The relationship between the requirements information at the different phases must be identified, represented and maintained. No matter what type of information is defined at any particular phase, there will be some elements of client requirements which relate back to requirements in the original program document. It is noted that the RIBA Outline Plan of Work project stages conclude at 'use'. This research has separately recognized and included an additional stage, which is demolition/decommission in order to cover for the entire lifecycle of a building. Similar identification of lifecycle phases was made by Edum-Fotwe and Price (2009) who indicate that this would include all activities deemed essential for executing the feasibility and business case, pre-design, design, build, operate, maintain and refurbish reuse and final decommissioning of a building.

eRIM classifies the lifecycle phases into two categories: (i) project lifecycle which covers all activities from preparation to end of construction (i.e. when the project is completed and the building handed over to the client. (ii) building/facility lifecycle encompasses all activities from preparation and brief to design, construction, handover, use/operation of the building until its end-of-life (i.e. when the building is demolished or decommissioned and/or used for other purposes other than those for which it was originally planned). Recognizing the significance of managing requirements information across all phases, eRIM specifies that 'requirements information management' be conducted throughout the lifecycle of a building, encompassing both project and facility lifecycles. This, according to eRIM, means that the activities to manage client requirements should be integrated at each of the lifecycle phases. Kiviniemi et al. (2004) and Kiviniemi (2005) conceptualized a similar approach with key elements as a 
Jallow et al 2017. "An enterprise architecture framework for electronic requirements information management.” International Journal of Information Management, 37(5), 455-472.

proposed model for lifecycle client's requirements setting and management, and linkage between Requirements Model and existing Building Product Model to support interaction between requirements and design solutions. There are several components at the lifecycle phase level. These are (i) standard document layer, and (ii) requirements information layer.

\section{i. Standard Document Layer}

Conventionally, there is lifecycle information on standard documents that are generated and used at each phase. The information in these documents is produced and processed by the various application tools used at the phases. Currently, the trend is the use of BIM-based applications. Each of the documents is a carrier of client requirements or is generated to document client requirements during construction and facilities management. Consequently, the documents need to be identified and categorized under each phase. eRIM defines a 'standard document layer' for the specification of these documents. This research identifies some of the standard documents and information generated at each phase of the lifecycle. These are for the purpose of demonstration and are by no means exhaustive. East and Nisbet (2010) identify through COBie, commonly required information artifacts produced during the facility lifecycle mostly in paper form and are distributed between project teams; and form basis for discussion and sometimes demonstration.

\section{ii. Requirements Information Layer}

Following the identification of the documents at the 'standard document layer', it is prudent that the information is adequately stored in a manner to support collaborative and distributed access. To facilitate storage, requirements information within those documents has to be identified, extracted, transformed and loaded into the repository. A 'requirements information layer', is defined which will serve as a funnel between the applications that produce the documents in the 'standard document layer' and the repository. It is to serialize requirements information from various sources within the lifecycle and structure the information into an appropriate format of the repository. This would potentially mean capturing and storing any information relevant to the client requirements in the documents. Relationships between requirements should be established and specific attributes should be identified to serve as dependency links between related requirements across the lifecycle as shown in Figure 4. Establishing the dependency could be implemented as manual or automatic. However, it is preferred to be automated for greater efficiency.

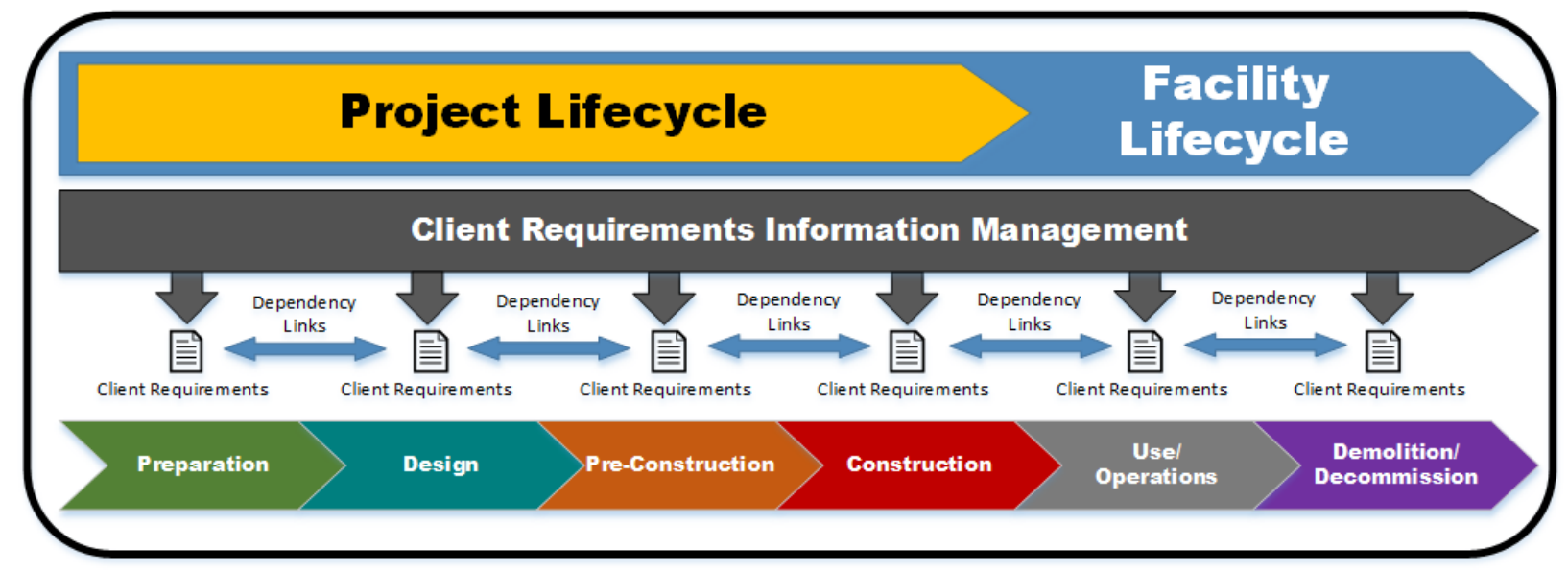

Figure 4: Requirements dependency links across the lifecycle phases:

The standard document layer and the requirements information layer are demonstrated within the lifecycle phases and presented in Figure 5. This figure gives a representation of the entire lifecycle phases with layers and example documents used therein. The process for creating the requirements management 
Jallow et al 2017. "An enterprise architecture framework for electronic requirements information management.” International Journal of Information Management, 37(5), 455-472.

elements and all related entities described earlier for the lifecycle phases, as the first component of eRIM, is summarized below.

- Identify standard construction documents at the 'standard document layer'.

- Extract client requirements information at the 'requirements information layer'.

- Structure the requirements information in an appropriate format according to the database schema of the repository to enable storage and to facilitate the drive for collaborative access.

- Identify requirements attributes to be used as a 'mapper' to the program document (The mapper is a requirement identifier that links related requirements which is essential for traceability and dependency checking across the lifecycle).

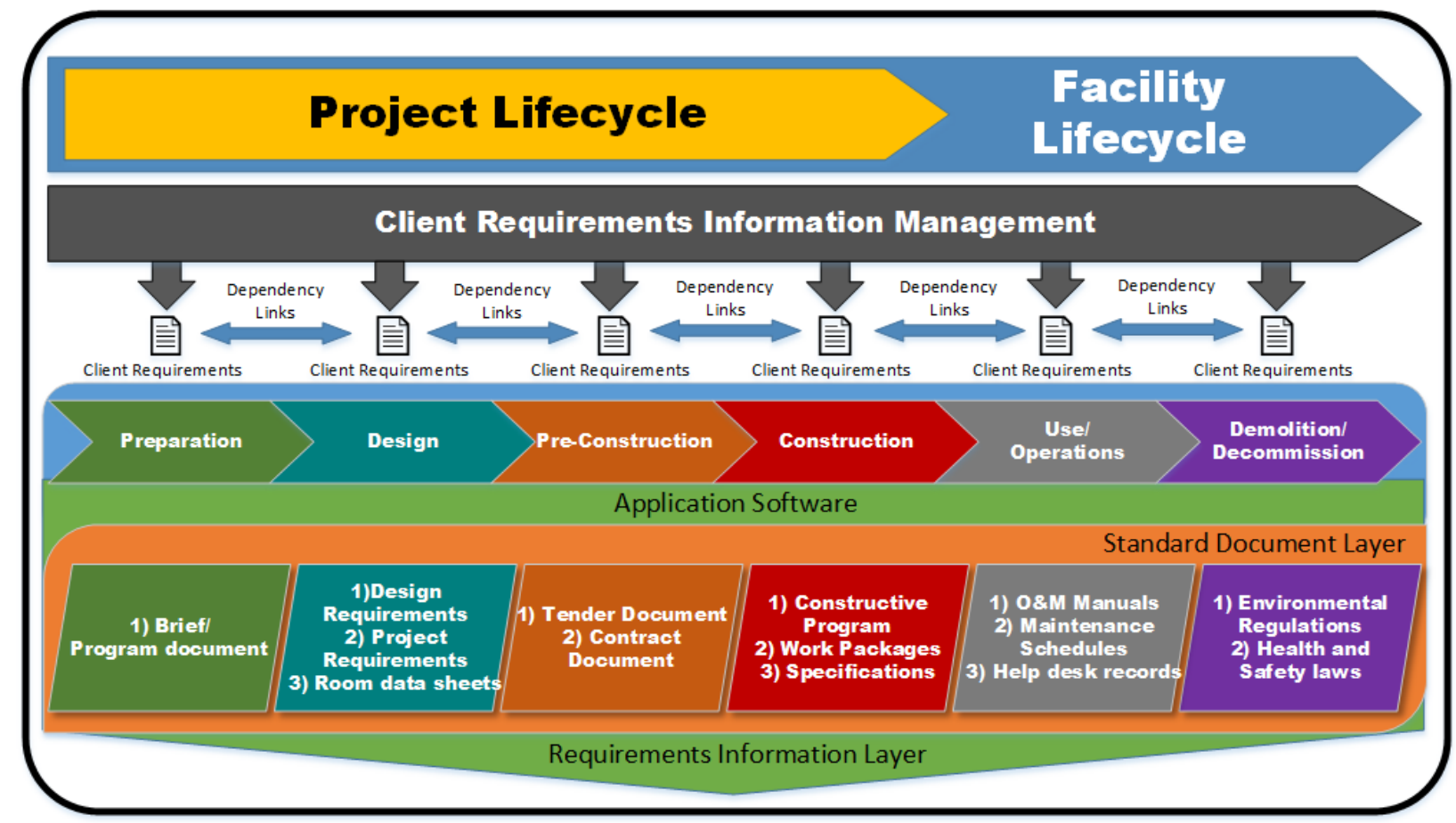

Figure 5: Lifecycle phases showing standard documents and requirements information layers

\subsubsection{Requirements Repository}

Client requirements, as defined at each project phase, should be stored in the repository within a separate requirements library module designed for that phase. A module is an individual requirements store for each lifecycle phase. Dependent requirements should be mapped between modules to provide traceability and indicate dependencies between requirements necessary for impact analysis of changes. New requirements should be added into the repository no matter the medium (online form, telephone, Email, paper form, verbal instructions through face-to-face or at meetings) used for its creation. Alternatively, information on requirements can be recorded in an external document which can then be directly imported into the repository. This extraction and importation into the database could be either manual or automatic. Such external documents need to be specifically structured and formatted according to the data schema of the individual modules of the repository. In order to automate this manual input of information in the database, it is suggested that the system used to document the initial documents at each phase be integrated with the repository.

The database schema should support detailed requirements information storage and should include attributes such as requirement type, description, rationale and priority. The schema should support 
Jallow et al 2017. "An enterprise architecture framework for electronic requirements information management.” International Journal of Information Management, 37(5), 455-472.

standard data/information specifications to define construction related information. This will be catalyst for requirements information flow between various phases and systems. Therefore, it is recommended that standard formats for information exchange should be adhered to in order to facilitate this process. Rationale (i.e. information on why a particular requirement is needed) is considered a key attribute, as it is essential in understanding changes and their impact. It can also prevent people from making incorrect assumptions on requirements. Priority indicates the importance or urgency of a requirement to the development of the project.

The repository should provide up-to-date and real-time requirements information, as a centralized storage, which can be accessed concurrently by distributed teams at different locations. Project team members, subject to roles and authorization, should be able to log-in to the repository and create/view/edit requirements.

Different business processes and applications are used at various phases of a project to facilitate activities of those individual phases. For example, a material procurement system is used to order construction materials (i.e., a business process). Such applications carry information associated with requirements yet they stand independently. It would therefore be important to integrate such applications and processes (e.g. the material procurement process and system with the requirements management system via services to validate orders (i.e. to check for compliance) before they are placed. This is vital in the effort to reduce the purchase of materials that do not meet requirement specifications. It can also reduce waste created by erroneous orders by ensuring the correct orders are made in the first place, and also reacting to changing requirements after the orders are placed. In the end, this integration will help streamline the procurement processes with the requirements management processes and to add value to the entire construction process. Similar integration of other lifecycle phases can also be instituted. The following activities should be performed in addition to those of the lifecycle phases when implementing and using the repository.

- Design and develop the database schema according to requirements attributes.

- Implement the database to support collaborative access by distributed teams.

- Store the requirements information within the repository which is essential for consistency, accuracy and completeness of requirements information. The information should be structured or should be based on standard information specifications for storing construction related information. Such standards include the Industry Foundation Class (IFCs) data schema, Express, Extensible Mark-up Language (XML), JSON, etc.

- Integrate the repository with common construction application software used at various project phases to facilitate information exchange.

\subsubsection{Dependency Management within the Repository}

In order to provide efficient and effective traceability between requirements within the repository, dependency links need to be indicated between dependent requirements for traceability purposes. eRIM specifies three types of dependency links, namely: no dependency, strong dependency and weak dependency. The links are directed and represented by arrows (i.e., solid and dotted) with the arrowhead pointing at the direction of the impact. A dependency may occur between primary requirements or between a primary requirement and a bottom-level requirement (i.e., secondary requirement).

- A strong dependency exists where there is maximum constraint between two or more primary requirements or between a primary requirement and a secondary requirement. A strong dependency link is represented by a solid arrow line. Where a strong dependency exists, a change in one of the requirements will have an impact on the depending requirement(s).

- A weak dependency exists where there is minimum constraint between primary requirements or between a primary requirement and a secondary requirement. A weak dependency link is 
Jallow et al 2017. “An enterprise architecture framework for electronic requirements information management.” International Journal of Information Management, 37(5), 455-472.

represented by a dotted arrow line. Where a weak dependency exists, a change in one of the requirements will have an impact on the depending requirement(s). However, this impact may be very minimal or uncertain to occur at all.

- A 'no-dependency' link exists where there is no direct dependency between requirements and no representation is made in this instance.

For example, a dependency link between two primary requirements, e.g., 'Primary Requirement A' and 'Primary Requirement B' as illustrated in Figure 6 could be strong or weak in either direction. However, a link from a primary requirement to a secondary requirement(s) will be a 'strong link'. In this case, the arrowhead points towards the secondary requirement(s), which will be impacted when there is a change. Similarly, a link from the secondary requirement(s) to a primary requirement will be a 'weak link' as demonstrated in Figure 7 and Figure 8. That means a change in a secondary requirement can never have a major impact on a dependent primary requirement. In this case, the arrowhead points towards the primary requirement, which may have minimal impact or none at all when there is a change in the secondary requirement. Secondary requirements are represented in 'room data sheets' as illustrated in Figure 8.

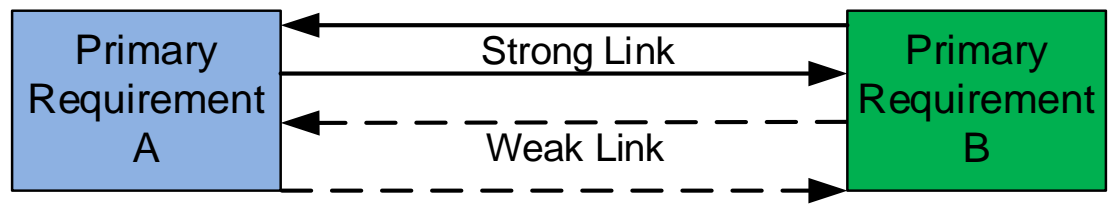

Figure 6: Links between two primary requirements 
Jallow et al 2017. "An enterprise architecture framework for electronic requirements information management.” International Journal of Information Management, 37(5), 455-472.

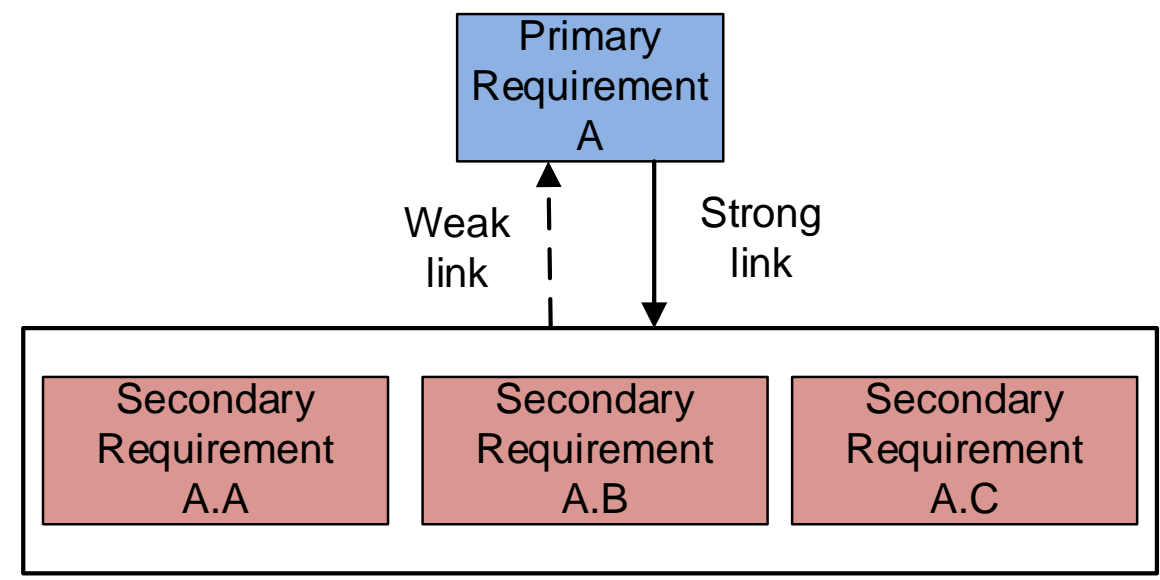

Figure 7: Links between a primary requirement and secondary requirements

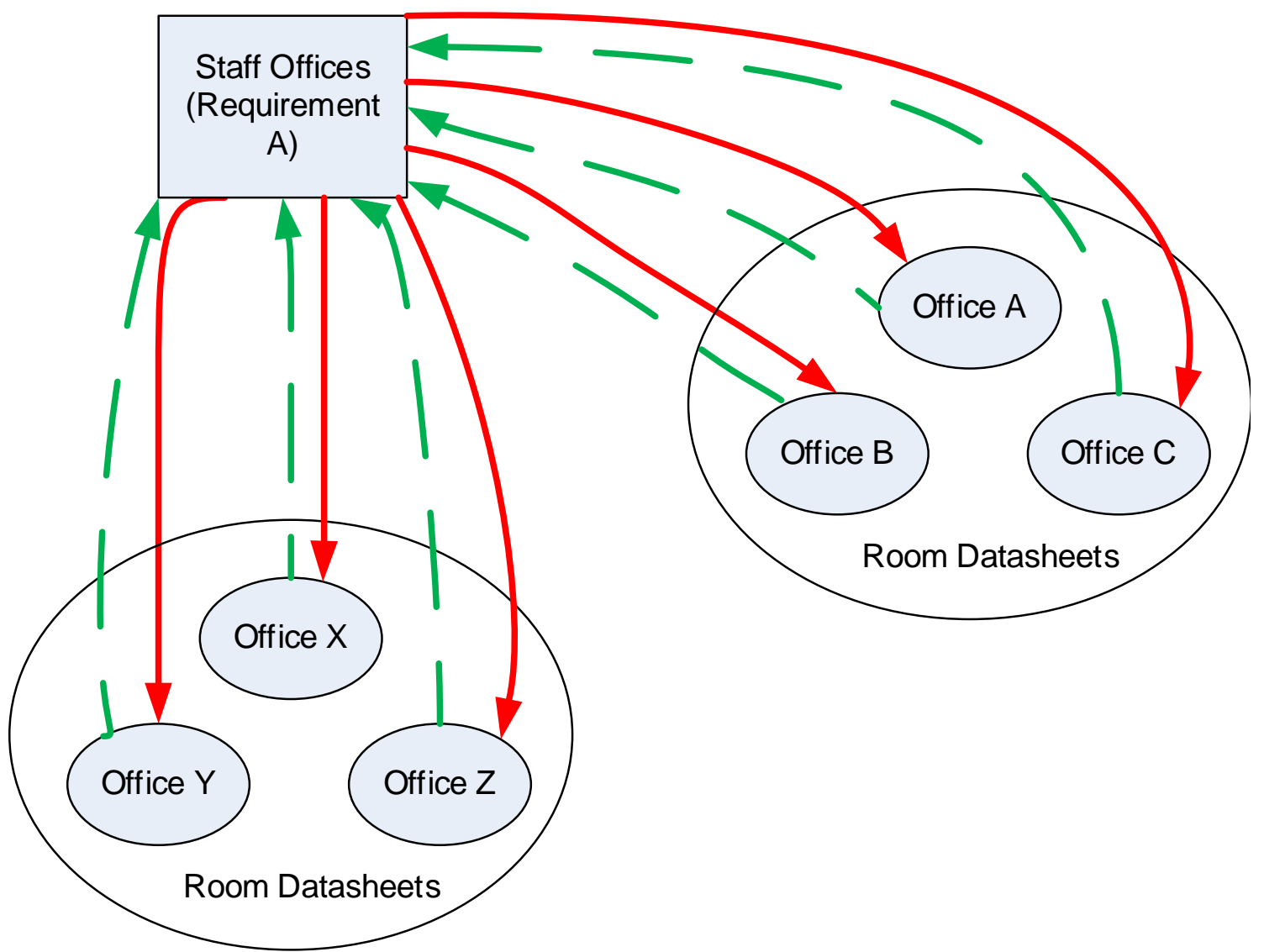

Figure 8: Links between a primary requirement and room data sheets

These dependencies can further be propagated between all types of requirements across the lifecycle phases, forming an integrated network of dependency links of requirements. Any dependency matrix implemented should factor the configurations of these links between requirements. 
Jallow et al 2017. “An enterprise architecture framework for electronic requirements information management.” International Journal of Information Management, 37(5), 455-472.

\subsubsection{Requirements Change Management Component}

Change management is an integral and essential component of the framework. Requirement changes should be executed under a coordinated approach to streamline the change process and assist in real-time capture of the change information. Different construction organizations may have different change management procedures or protocols in terms of execution. eRIM accommodates for these differences. Change may be requested through different channels as shown in Table 2: face-to-face (individually), team meetings, telephone, Email, paper-based (hardcopy) and on-line forms.

Table 2: Channels used for requirements change request

\begin{tabular}{|c|c|}
\hline Change Request Channels & Description \\
\hline Telephone & $\begin{array}{l}\text { Requesting a change by calling and discussing the } \\
\text { change but a formal change request accompanied with a } \\
\text { change control form will have to be raised }\end{array}$ \\
\hline Online Forms (eForms) & $\begin{array}{l}\text { Using an internet based form to request a change (not } \\
\text { used extensively in the case studies) }\end{array}$ \\
\hline Email & $\begin{array}{l}\text { Sending an Email with all change details and necessary } \\
\text { supporting documents as attachments }\end{array}$ \\
\hline Meetings & $\begin{array}{l}\text { Requesting a change during design and or project } \\
\text { progress meetings }\end{array}$ \\
\hline Face-to-face(individually) & $\begin{array}{l}\text { Meeting with an individual and verbally requesting a } \\
\text { change but a formal change request accompanied with a } \\
\text { change control form will have to be raised }\end{array}$ \\
\hline Paper-based (hardcopy) & $\begin{array}{l}\text { Using hardcopies of change order forms and sending } \\
\text { them through the post }\end{array}$ \\
\hline
\end{tabular}

However, no matter which channel is used to request a change, a formal change request process is followed and a change control form completed, emulating the procedure observed in the case studies. The information should also be processed through the change management system. This means change information should not be added into the repository through the Web database directly.

Requirement change management is regarded as a process-oriented activity and this research adopted a business process management (BPM) approach to manage all changes ensuring the synchronization of process activities and to integrate different processes, people and systems together with the information required to provide coordination and visibility. Process-orientation is vital to support collaborative working and information flow and facilitates integration of processes across a project's lifecycle. In his work on a data-centric, process-oriented model for effective collaborative working, Bacon (2009) states that the adoption of a technology solution, be it an extranet or a BIM, is unlikely to deliver value to the collaborating team or to the client if process is not embedded at the heart of collaborative working. A change request will be routed accordingly during the change management process as defined by the workflow with activities and tasks performed by both people and systems. As the BPM system is integrated with the repository, requirements information can be made available from the repository through the integration layer which can be used to analyze the impact of a requested change. This is dependency checking.

The 'requirements dependency checker' service searches the repository for all related requirements (i.e., both primary and secondary requirements) to the one proposed in the change request. This enables the user to assess the cost and time impact that could result from the proposed changes. Once the authorization is complete, the repository should be updated with the change information using the 'requirements updater' without any manual input. The update is done in such a way that the change information is added as a new version of the changing requirement whilst keeping the original for 
Jallow et al 2017. “An enterprise architecture framework for electronic requirements information management.” International Journal of Information Management, 37(5), 455-472.

historical purposes. The change process system then communicates that information to the initiator, and all stakeholders who may be affected by the change through Email notifications. The initiator will also get the information on the user notification section of the system. Table 3 shows the different criteria that the change management system has to meet as defined by eRIM framework with the description and rationale of each criterion. The system should be capable of capturing real-time process data during the change approval process. This data is then written to the repository in the 'change' module within the database which holds all change and version history. This module is also linked to the requirements module thus making it possible to trace all changes for each individual requirement. Figure 9 shows a high-level graphical representation of the request for change process that would require implementation into an automated change management system. The first activity 'Request Change' requires a change initiator to identify any changes and fill in a change request form. The various parts and information to be filled depends on who the initiator is and the type of change requested. This request can be initiated using any of the identified channels listed in Table 2. This form is sent for authorization and is received by the relevant authority, who then starts the necessary processing.

Table 3: Criteria of the change management system

\begin{tabular}{|c|c|c|}
\hline Criteria & Description & Rationale \\
\hline $\begin{array}{l}\text { Change Process } \\
\text { Coordination }\end{array}$ & $\begin{array}{l}\text { Streamlining, coordinating and } \\
\text { controlling the change request } \\
\text { process. }\end{array}$ & $\begin{array}{l}\text { Important to make sure the different } \\
\text { people involved in the change process } \\
\text { are integrated and that the process is } \\
\text { visible and auditable. }\end{array}$ \\
\hline $\begin{array}{l}\text { Dependency } \\
\text { Checking }\end{array}$ & $\begin{array}{l}\text { To check for dependency between } \\
\text { the changing requirement and } \\
\text { other related requirements. }\end{array}$ & $\begin{array}{l}\text { Important to trace relationships } \\
\text { between requirements and other } \\
\text { components which is crucial for } \\
\text { impact analysis of cost and schedule } \\
\text { as well as other requirements such as } \\
\text { value and benefits. }\end{array}$ \\
\hline $\begin{array}{l}\text { Requirements } \\
\text { Update }\end{array}$ & $\begin{array}{l}\text { Updating the requirements } \\
\text { repository once the authorization } \\
\text { process is complete. }\end{array}$ & $\begin{array}{l}\text { Important to make sure requirements } \\
\text { are updated during the project } \\
\text { development process so that people } \\
\text { work with the most up to date } \\
\text { requirements and capture the change } \\
\text { history. }\end{array}$ \\
\hline $\begin{array}{l}\text { Change } \\
\text { Notification }\end{array}$ & $\begin{array}{l}\text { Communication of change } \\
\text { information to the change initiator } \\
\text { and all those who may be affected } \\
\text { by the change through Email and } \\
\text { on the notification section of the } \\
\text { system. }\end{array}$ & $\begin{array}{l}\text { Important to make sure all those } \\
\text { concern are informed of changes on } \\
\text { requirements at the right time with the } \\
\text { right information. }\end{array}$ \\
\hline
\end{tabular}

The 'Process Change Request' task involves various sub-activities which require different participants to review the changes requested and decide either to approve or reject the changes as modeled in Figure 11. This would include checking for dependencies of the changing requirement in order to determine its cost and schedule impacts. It also involves assessment of effect on both time and budget. Once the approval process is completed, two highly important tasks ('update change' and 'communicate change') should be executed. 'Update change' requires updating the repository with the most-up-to-date information generated from the change process. 'Communicate change' requires that information is communicated to 
Jallow et al 2017. "An enterprise architecture framework for electronic requirements information management.” International Journal of Information Management, 37(5), 455-472.

all stakeholders especially to those for whom the change is relevant. This can be done through Email notifications. It is important to note that only the critical major steps of the change management process are shown on the architecture of the Framework illustrated on Figure 9.

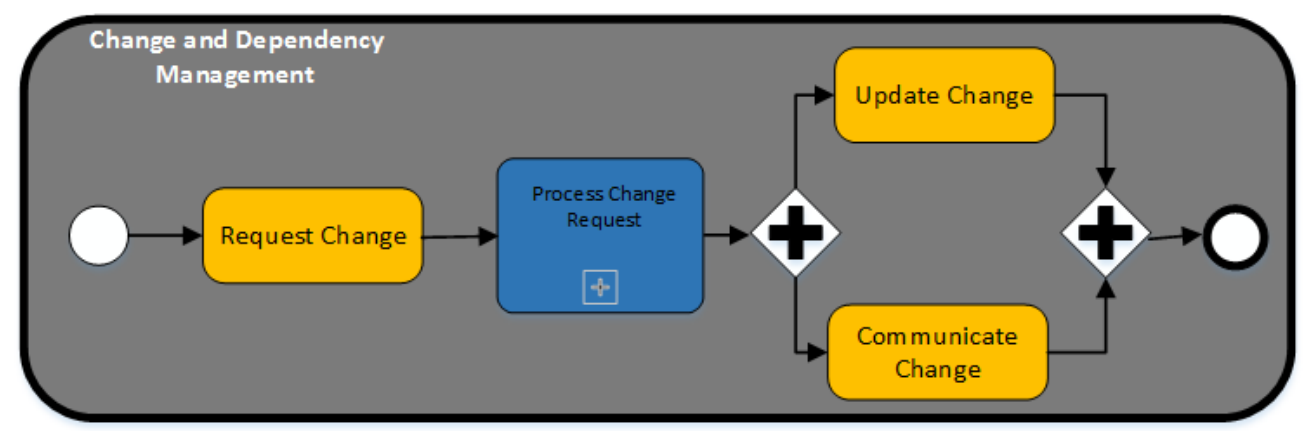

Figure 9: A high-level view of the request for change process showing core activities.

During full implementation, these would require expanded modeling using BPMN showing all the activities of the process including the sub activities grouped as 'process change request'; information flow and stakeholder interactions across functional units, roles and other systems (both internal and external). The sub-process of 'process change request' task is illustrated in Figure 10. Requirements management business services should be developed as 'services', which can be requested and accessed both internally and externally in the 'service composition' part of the framework. These business services need to support the requirements management process. Some of the recommended services to be developed include checking for dependences between requirements to facilitate impact analysis, (ii) real-time update of the changing requirement in the repository with the most recent information in the change request, (iii) retrieving specific requirements needed at any phase of the project, and a service to communicate and disseminate change information to the relevant stakeholders.

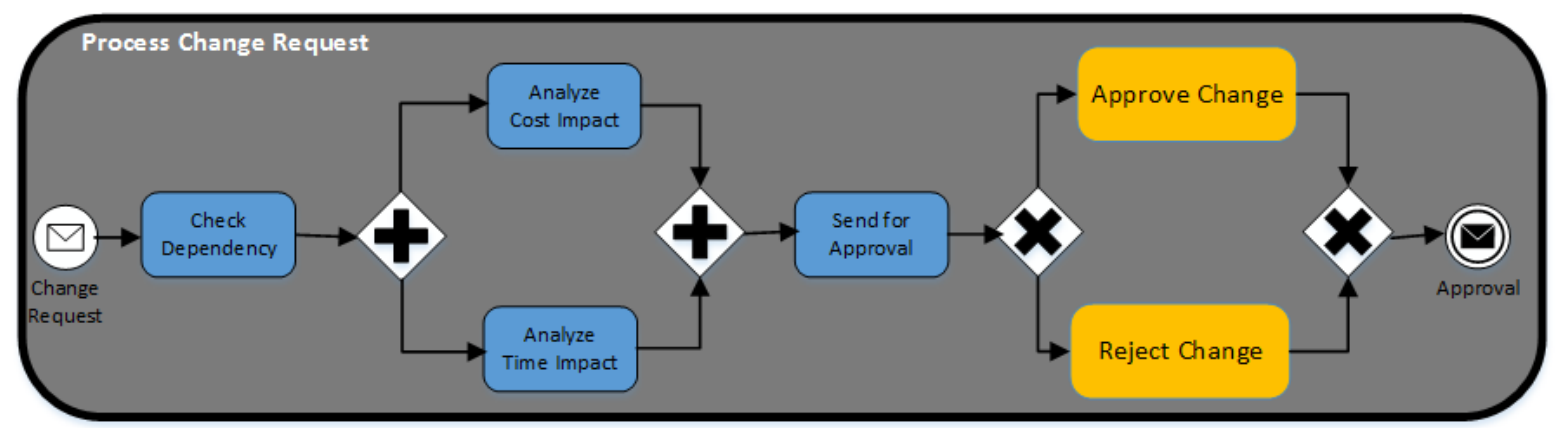

Figure 10: The sub-process of the high-level task - 'process change request' 
Jallow et al 2017. "An enterprise architecture framework for electronic requirements information management.” International Journal of Information Management, 37(5), 455-472.

In order to implement and use the change management system in practice, the following activities need to be undertaken:

- Develop a process map of the requirements change process: it is recommended for this to be developed using Business Process Management Notation (BPMN).

- Automate the process model into an executable process. For example, transform the BPMN model into Business Process Execution Language for Web Services (BPEL4WS): a Business Process Management Suite/System can be employed for this.

- Deploy the executable process by publishing the BPEL into a process engine/process server for execution.

- Define and develop the integration between the change system and the repository.

\subsubsection{Integration Layer and Approach}

The integration approach specified on eRIM is based on service-oriented architecture (SOA) philosophy, which is a crucial facilitator for integration between systems, and support for information exchange. The integration provides mechanism to intermediate between the different systems used for requirements processing throughout the lifecycle through data transformation, messaging and information sharing. With this mechanism, all the requirements related processes within the lifecycle phases can interact with the repository via the web services using SOAP, REST or any other appropriate mechanism as the communication and messaging protocol. The processes themselves can also be packaged as services, and can be invoked and used by other internal or external processes. This will facilitate an integrated business process requirements management across the lifecycle phases. Information exchange between the change management and repository is also facilitated through this integration approach. The eRIM framework showing all the constituent components and their interrelation is depicted in Figure 11. 
Jallow et al 2017. "An enterprise architecture framework for electronic requirements information management.” International Journal of Information Management, 37(5), 455-472.

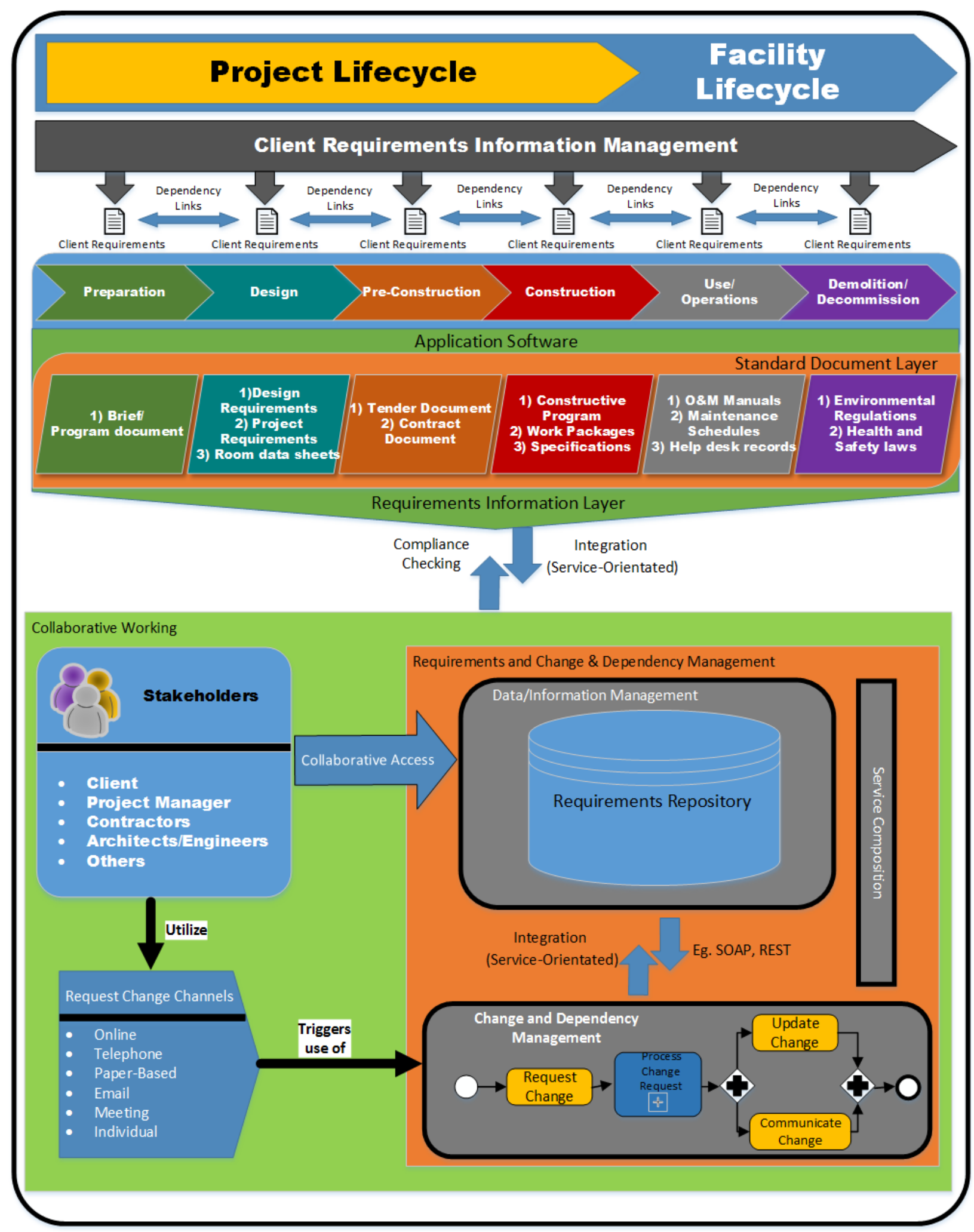

Figure 11: eRIM Framework 
Jallow et al 2017. "An enterprise architecture framework for electronic requirements information management.” International Journal of Information Management, 37(5), 455-472.

\subsection{Requirements Management Role}

Personnel from several functional areas within a construction project are currently responsible for capturing and managing the client requirements. The client, architect, consultants, project manager (PM), quantity surveyors (QS) and cost consultants (CC) all play key roles in managing the client's requirements. The designer and contractor play a major role because they focus on transforming customer needs, expectations and constraints into design solutions and supporting them throughout the construction process. With the several parties involved, it becomes cumbersome to identify who is responsible for the management of the requirements. In other areas of the construction process, specific role(s) are created to be responsible for specific management tasks and activities. Within other product development sectors such as manufacturing, aerospace and software, 'Requirements Managers' are hired specifically to be responsible for customer requirements (Schmidt and Souza, 2007). Within the construction industry, there is currently no standard role responsible for specifically managing client requirements. Given the difficulty of managing client requirements as observed during the research, it emerged while formulating eRIM that a role is necessary to take charge of managing the requirements during project implementation. Therefore, it is recommended that a 'Requirements Manager' role be incorporated within the project team which is important in contributing towards successful projects. A similar recommendation was made by Lee and Egbu (2008) who state that the appointment of capable expert consultants is important to ensure that client's project requirements are fully met.

\subsection{Implementation of the Framework}

A prototype software system based on the eRIM framework was developed to demonstrate and evaluate its functionality within construction projects. This section is aimed at presenting a brief description of how the framework was implemented into a software prototype and not to dwell on the development of the software prototype itself. The full details of the system development are beyond the scope of this paper. Any detail elaboration would detract from the focus of this paper, which is on the framework, and not the software. eRIM specifies a requirements repository and change and dependency management systems be implemented. As a result, MySQL database management system was used to build the centralized repository, and PHP as the scripting language for the web application including the user interface. To proceed, the end user requirements of the system needed to be established. Consequently, it was crucial to identify the core business processes of requirements management process, and understand the business rules, which describe the constraints on the data to be stored in the database (Connolly \& Begg, 2010). Consequently, the business rules were defined which explicitly helped identification of the different actors, their relationships and a conceptual view of the interactions between them. They were established through observation of the requirements management process, examination of requirements and their related documents such as brief and change order forms amongst others as well as interviews with clients (or their representatives) and project managers. This helped in establishing what information is needed in the database, e.g., the database entities, attributes, relationships as well as their integrity constraints as well as formulation of the functional requirements of the prototype system. Following this, the database schema was produced and tables (to store requirements information) and queries developed.

The change and dependency management system is developed using a business process management suite/system to develop the process model and orchestrate that into an executable automated change and dependency management system (CDMS). This was done first by modelling the change request process of the case studies described in this research. Consultation was done with the project managers to determine the structure of the project organizations and the activities of the requirements management process. This also included consultation of the various actors, tasks and information sources of the change request process. The process model described the activities, tasks, steps, resources, participants/actors (both humans and system) and information flow of the change request process. The process model was then transformed into an executable process using BPEL; deployed and executed through the process 
Jallow et al 2017. "An enterprise architecture framework for electronic requirements information management.” International Journal of Information Management, 37(5), 455-472.

engine/server. The system is accessible through a portal, which enables central log-in to serve as the 'central access point' to both systems (repository and change management system), thus eradicating the need to switch between the two systems components.

The integration between the repository and the CDMS is base on Service Oriented Architecture (SOA) philosophical approach with Web Services as the integration technology. Web services - a software component designed to facilitate interoperable machine-to-machine interaction over a computer network, and support the execution of business processes. In this way, information in those documents held in the source computer systems can be sent seamlessly to the database by invoking the web services developed for that purpose. Another proposition is that multiple Web Services of specific requirements management activities should be developed for use at various phases. These services will facilitate seamless interaction with the repository for functions such as requirements update and dependency checking. When implementing the CDMS in an organization, the following activities need to be undertaken: (i) develop a process map of the requirements change process: This can be developed using Business Process Model and Notation (BPMN) - recommended; (ii) automate the process model into an executable process. E.g. transform the BPMN model into Business Process Execution Language for web services (BPEL4WS): a Business Process Management Suite/System can be employed for this; (iii) deploy the executable process by publishing the BPEL into a process engine/process server for execution; (iv) define and develop the integration between the CDMS and the repository based on SOA and technology. It is important to note that only the key steps of the change management process are shown on the framework (Figure 11) for illustration purposes. During full implementation, these would require expanded modeling using BPMN showing all sub-activities, information flow and their interactions across functional units, roles and other information systems (both internal and external).

\section{Evaluation of the Framework}

A group comprising industry experts and practitioners was convened for the industrial evaluations. This group is representative of the intended use of eRIM by project managers, designers and engineers. Participants were drawn from the case studies construction projects. Two sets of evaluations were carried out with a total of eight participants. The first comprised four client project managers. The reason for selecting project managers is because they are the main class of stakeholders who manage the client requirements and are charged with the implementation on behalf of the client. Further rationale for their selection is that the Framework was developed based on observations conducted of the project managers managing the change requests submitted by designers and engineers. Therefore it was deemed fitting for them to evaluate the applicability of the framework using change orders already submitted to them. The second set of evaluations included: two architects, a project management consultant and a construction project manager. Since the framework was aimed at improving the requirements management process, it was considered fitting for these sets of experts to provide evaluation in order to determine how the framework can affect the current mechanism of requirements information management of which they are heavily involved. A structured evaluation process was designed and followed during the evaluation process. At the beginning of each set of evaluation, a presentation was made outlining the research problems, aim and objectives including a detail description of anticipated deliverables. The research methodology was also described in order to give an insight on how the proposed solution was reached. Following this, the eRIM framework was presented and all components described in detail.

It was relevant and also appropriate for the evaluators to test directly the functionality of framework in order to determine its relevance to industry. Consequently, they had the opportunity to demonstrate the framework through the prototype system, which implemented the underlying concept of the framework. The requirements repository was already pre-populated with the requirements of the projects, and during the demonstration process, twelve change requests were used with varying requirements details and complexity. These were real requirements changes submitted by designers, engineers and the client of the three projects that were observed. Dummy user accounts were created for the purpose of the evaluations. 
Jallow et al 2017. "An enterprise architecture framework for electronic requirements information management.” International Journal of Information Management, 37(5), 455-472.

The accounts included the following roles: (i) change requester, (ii) change reviewer and (iii) change approver. The evaluators used these accounts to log-in to the system assuming different roles at different stages of the approval process. Each evaluator used data captured on the change request forms to initiate a change process, and followed the progress of that change throughout the approval process. As a result they were able to test the following functionalities:

- $\quad$ Log-in to the system and initiate a changes process.

- Access and use of the features of the user interface.

- Route change request form between the various participants.

- Test access privileges of the various roles involved in the approval process, and executing the task that each role/participant performs during the process.

- Review of dependencies and impact through the automated mechanism of checking for dependencies and information presentation.

- Demonstrate and review change notifications (confirm information is sent to relevant stakeholders automatically).

- Review and confirm the update of the repository with new change information.

Discussions were also carried out on how the features solve the defined problems in an integrated manner. The evaluation results were captured from the questionnaires that were completed by the participants. A quantitative approach was used to present the data which were then analyzed and discussed. The questionnaire also included a portion which captured qualitative data (free text) from the participants, which was also analyzed qualitatively.

During the evaluation, participants/evaluators were asked to rate their perception of the potential of the electronic requirements information management (eRIM) framework and the prototype system for effective management of information about client requirements in the construction sector. In tabulating the quantitative data, each of the evaluation statements is presented with statistical data in the graphs in the following section.

\subsection{Discussion and Analysis of the Evaluation}

\subsection{1 eRIM clearly defines a solution to client requirements information management problem.}

eRIM specifies a structured and controlled requirements management process that registers client requirements after the production of the brief; design and construction and all through the life of the building. It ensures that details of client requirements are available at all times; provides a history of previous changes to requirements and enables the project manager to manage requirement changes effectively through a coordinated and controlled change management process. Most of the evaluators agreed that a solution has been defined with only one of them undecided as shown in Figure 12. The reason for the indecision was that the nature of the dependency links between requirements within the repository needs to be determined to establish how they should be implemented. But the evaluator was convinced that once that is ascertained, eRIM would solve the stated problem. 
Jallow et al 2017. “An enterprise architecture framework for electronic requirements information management.” International Journal of Information Management, 37(5), 455-472.

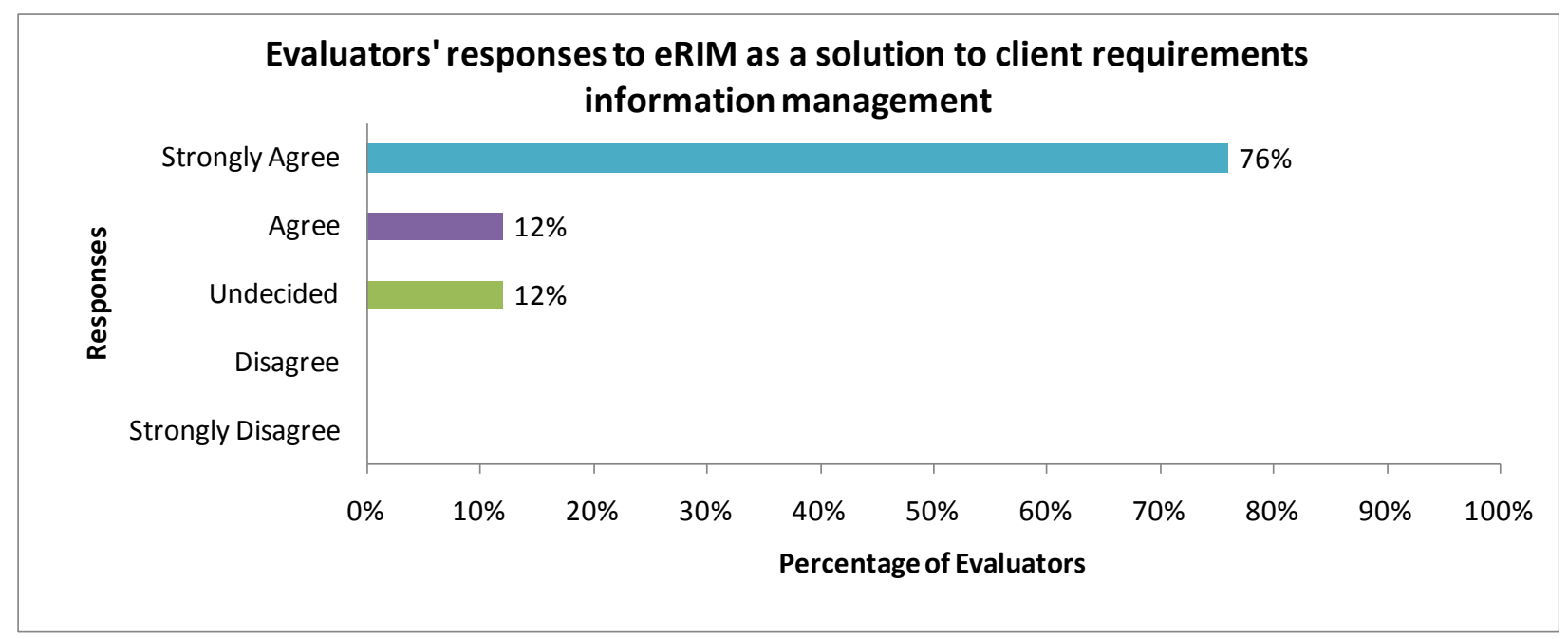

Figure 12: Evaluators' responses to eRIM as a solution to client requirements information management problem.

It is important to state that the mechanism and nature of the dependency links are issues identified by the research that need further investigation. However, it is clear that the concept had been adequately defined and it is a matter of implementation and not what is required to be implemented that needs further study.

\subsubsection{The integrated and centralized web database system will facilitate collaborative access to client requirements information management.}

The web database system serves as a central repository for client requirements information. This system can be accessed by project stakeholders through a web interface over the internet no matter of individual's geographical location (i.e., at anytime and anywhere) depending on roles and access authorization rights. The centralized repository approach will ensure that everybody works with the same and most up-to-date version of the requirements rather than having silos of requirements information.

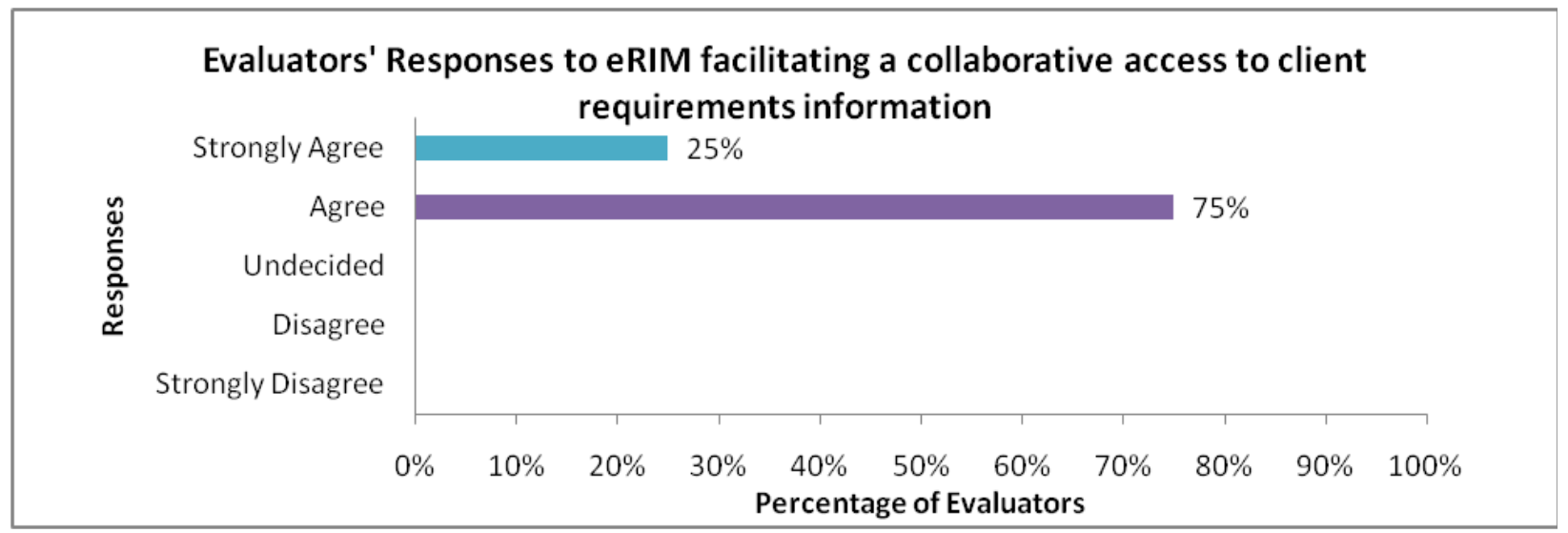

Figure 13: Evaluators' responses to eRIM to facilitate a collaborative access to client requirements information

Evaluators (according to the results) agreed that this approach and the system will facilitate an improved collaborative access as shown in Figure 13. Discussions to this effect were made that sometimes different team may work on different versions of requirements information which could potentially result in defects resulting to re-work. 
Jallow et al 2017. "An enterprise architecture framework for electronic requirements information management.” International Journal of Information Management, 37(5), 455-472.

\subsubsection{The dependency links defined in the prototype will enhance traceability between requirements.}

Traceability is crucial in requirements information management which according to eRIM can be facilitated by defining dependency links between related requirements. All the evaluators agreed to this statement as shown in Figure 14 but emphasized the need for proper implementation of the dependency links.

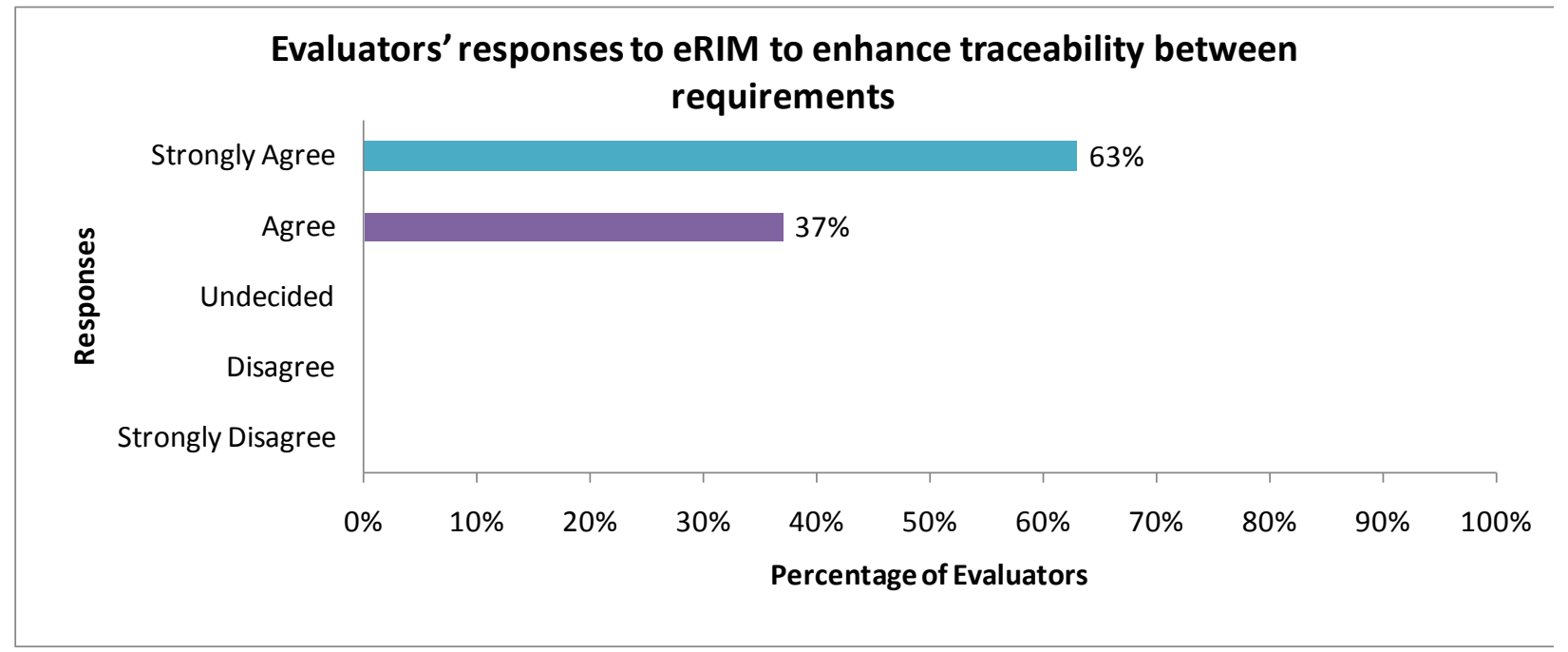

Figure 14: Evaluators’ responses to eRIM to enhance traceability between requirements

This is however regarded as an important development because currently the mechanism of checking for dependency during changes is manual and not efficient and could result in errors. Therefore, the feature to automate checking for dependencies will hugely enhance the change request and approval process.

\subsubsection{The change management component will improve the manual and paper-based request for changes process.}

A greater number of the evaluators had either agreed or strongly agreed to this statement with a single participant undecided as shown in Figure 15. According to the participant, this is based on the fact that the functionality of the change management component entirely depends on the manner on how the requirements are initially stored within the repository. Although, it was agreed during the discussions, that the approach to automate the change request and approval process was an improvement and a desired feature. 
Jallow et al 2017. “An enterprise architecture framework for electronic requirements information management.” International Journal of Information Management, 37(5), 455-472.

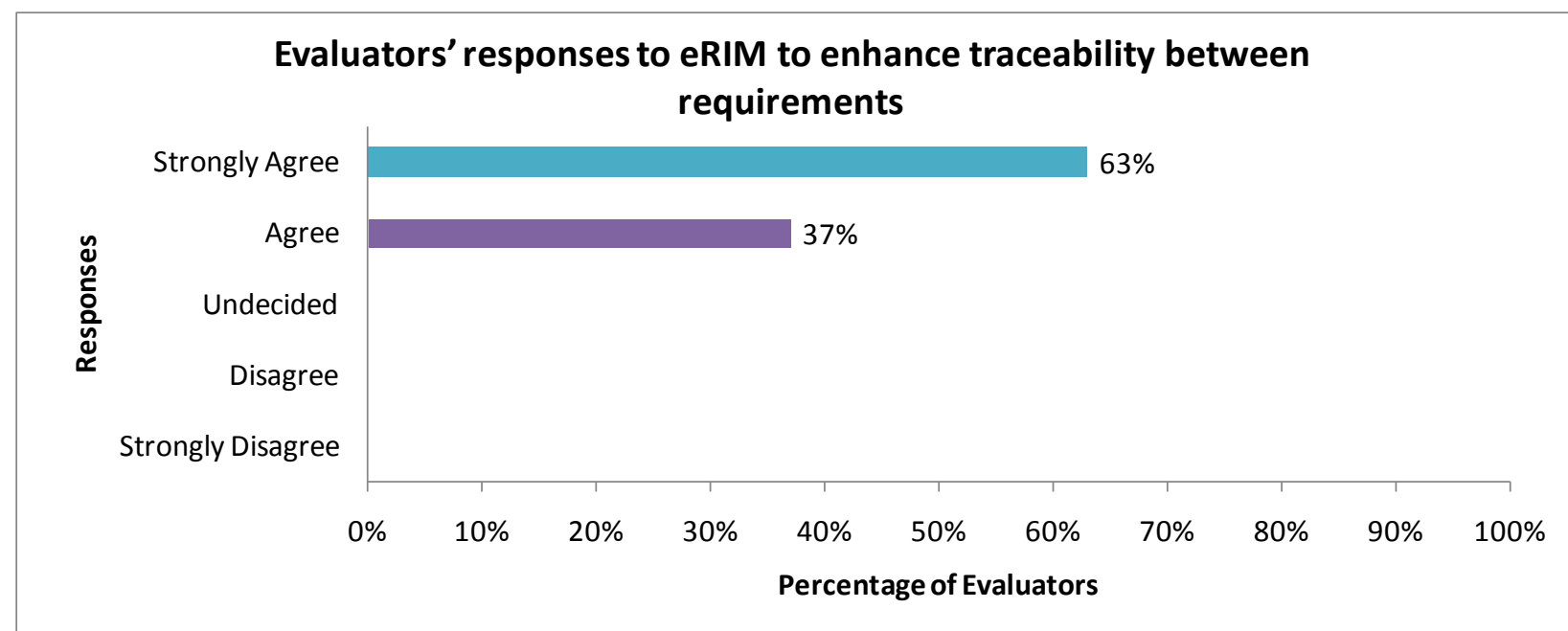

Figure 15: Evaluators' responses to eRIM change management component to improve the manual and paper-based request for changes process.

\subsubsection{The change management component provides a better approach to updating requirements information.}

Generally, updating client requirements information in the original brief after a change is authorized was virtually not carried out in the case studies. In most cases, the design is updated with changes and not the original brief document. It was also virtually impossible to update all the different versions of the requirements that may be with different people at different locations. The change management system integrated with the requirements repository has the capability to update client requirements information using a web service 'requirements updater'.

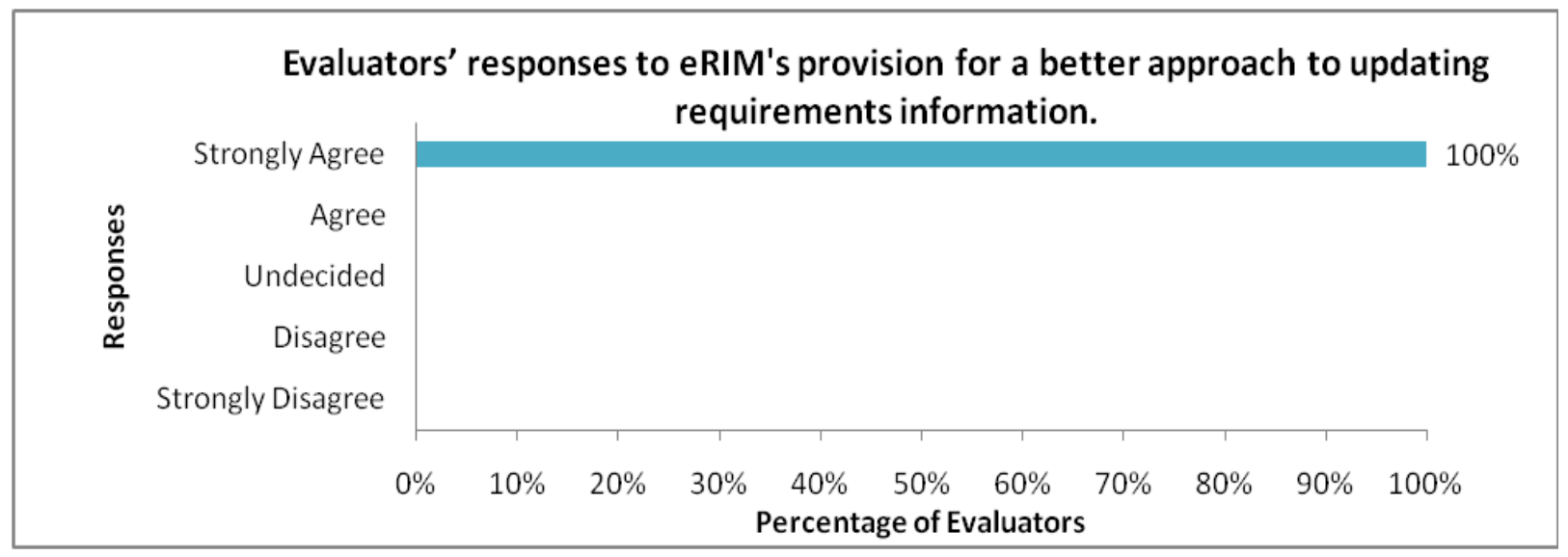

Figure 16: Evaluators' responses to eRIM's provision for a better approach to updating requirements information.

Without this web service and the central repository, it will require manual input of change information to the brief document and also on all other requirements documents in silos held by the different parties and in heterogeneous applications. Evaluators largely agree that this functionality within the change management system provides a better approach to updating requirements information as shown in Figure 16. 
Jallow et al 2017. "An enterprise architecture framework for electronic requirements information management.” International Journal of Information Management, 37(5), 455-472.

\subsection{General Observations}

It was observed that none amongst the focus group participants indicated to have used or experienced an approach (i.e., an integrated requirements repository and change management) of this nature to manage client requirements information in construction projects. Dependency links employed in eRIM were regarded as very useful in specifying traceability between requirements and no known system that they used before had such functionality. Reference was made to project extranets such as 4project and BIW but neither was understood to take the dependency links approach employed in eRIM. The dependency checking feature was also regarded as very useful in identifying dependent requirements of a changing requirement, which currently is manual and depends on intuition and experience. Dynamism of routing change requests was another area the evaluators thought could be enhanced to improve the functionality of the prototype. Currently, the routing process within the framework is pre-determined according to the process model. This means the steps a change request goes through for approval and the participants involved is predefined. However, evaluators thought it necessary that some tasks within the process need to be flexible allowing a user to determine who to route a task to instead of following a prior defined route. This they regarded relevant as sometimes a process may require specialist or urgent action from other participants not defined in the process.

The evaluation results indicated overwhelming interest from the participants to consider possibility of implementing the change management component of the framework as a drive to automate the request for change process.

\section{Conclusions}

In this paper, the electronic Requirements Information Management (eRIM) Framework has been presented. The innovation of the framework is that (i) it defines a lifecycle approach to managing information about client requirements, and (ii) it specifies an information-centric, process-and serviceoriented approach to managing the requirements.

Information-centric focuses on managing the content of documents instead of the conventional documentcentric orientation to the management of requirements information.

Process-oriented specifies a business process management (BPM) approach to manage all changes ensuring the synchronization of process activities and to integrate different processes, people and systems together with the information required to provide control, coordination and visibility. Process-orientation is vital to support collaborative working and information flow and facilitates integration of processes across projects lifecycle.

Service-oriented is to regard the development and operationalization of software systems from the viewpoint of 'services' (i.e., independent software components) that perform specific functionalities for managing requirements information, and how they can be integrated, requested and consumed.

The dependency checking feature for impact analysis based on the defined weak and strong relationships between Primary and Secondary requirements is novel in the field of requirements management in construction.

The Framework comprises two main components; a requirements repository and change and dependency management component. A third component is a supporting scheme (i.e. lifecycle phases) which defines the identification of all requirements related information at each phase in a layer called 'standard document layer'. Another layer, 'requirements information layer' was also defined within the lifecycle phases on which requirements information will be extracted from the standard documents for storage in the repository. Based on the combination of the advantages of Web database systems and business process management, the framework embeds information and change management functionalities of client requirements management in a unified fashion across the lifecycle. This approach identifies 
Jallow et al 2017. "An enterprise architecture framework for electronic requirements information management.” International Journal of Information Management, 37(5), 455-472.

requirements at each phase of the project. Requirements information derived from each phase is stored in the repository with related requirements mapped using a unique identifier. This ensures traceability between requirements which is crucial in enabling dependency checking to facilitate impact analysis when considering change requests. The change management component will be used to enhance the requirement change process by enhancing the coordination and control of the change request process. This will define the roles of project teams, activities, and resources and their interrelation and interaction during the change management process. The system will also facilitate and enhance visibility and auditability of the process and help integrate the different systems used so that information can be shared and exchanged. It can also contribute towards historical knowledge creation on all changes that occurred during a building lifecycle.

The expected benefits of eRIM are to contribute towards enhancement of an integrated project team (client, contractors, users, constructors, suppliers, etc.) and processes (from programming, design, construction all the way to operation and demolition or decommissioning). An integration layer is specified to provide integration and facilitate interoperability between the systems, and exchange of requirements information between the change management component and the repository. The results also indicate the need for the role of requirements information manager.

The framework forms the basis for the design, development, and evaluation of a requirements management system. The evaluations demonstrated the applicability of the framework. It is expected that when adopted and implemented in the construction business processes, eRIM will better the requirements information management process in construction projects lifecycle. eRIM can be used in other development projects such as oil and gas and manufacturing. However some of the components would need to be modified to match the specific domain - for example the life cycle phases, the requirements information architecture, and the process of managing their changes.

Future work should include testing the applicability of the framework through the evaluation of the associated software system. The IT tools identified for the development of the software system include the use of BPMN and BPEL for requirements process modeling and execution of the change and dependency management component respectively. The main limitations of the framework are:

- It is important that further research is conducted to find out the suitability of eRIM in the later phases of the lifecycle (i.e. from use/operation and demolition/decommission). Due to time constraints, enough data could not be collected for these two phases and as a result, sufficient test could not be conducted during the development and evaluation of eRIM. However, the concept of managing requirements which is common to all phases has already been established by eRIM; nonetheless, further tests need to be conducted so that proofs on functionality and robustness are established.

- Construction project extranets (i.e., the use of a central server for managing construction documents) have been and still continue to be used in facilitating project information and document management. Such information and document is the brief which is used to develop the design. It is therefore crucial to explore the possibility of incorporating eRIM within project extranets such as 4projects.

- BIM has emerged as a solution to capture and make available the whole lifecycle information of a facility. Current research in BIM made limited progress on how client requirements is captured and managed. eRIM defines a philosophical approach to better management of the whole lifecycle client requirements information in a manner that can integrate people, processes and systems. This is in line to the BIM philosophy and process thus its amalgamation as a model component will immensely compliment current trends. Therefore, further research needs to be employed to investigate how eRIM can be integrated within a BIM environment as a client 
Jallow et al 2017. “An enterprise architecture framework for electronic requirements information management.” International Journal of Information Management, 37(5), 455-472.

requirements information management module. Although already the design of eRIM based on service and process orientation sets a solid foundation to enable this. External BIM applications can request and consume eRIM services to retrieve requirements information, which can be transformed into a format for use by a particular application. 
Jallow et al 2017. "An enterprise architecture framework for electronic requirements information management.” International Journal of Information Management, 37(5), 455-472.

\section{References}

Abdul Karim, N. S., \& Hussein, R. (2008). Managers' perception of information management and the role of information and knowledge managers: The Malaysian perspectives. International Journal of Information Management, 28(2), 114-127.

Alalwan, J. A. \& Weistroffer, H. R. (2012). Enterprise content management research: a comprehensive review, Journal of Enterprise Information Management, 25(5) pp. 441-461.

Alshubbak, A., Pellicer, E., Catalá, J. \& Teixeira, J. M. C. (2015). A model for identifying owner's needs in the building life cycle. Journal of Civil Engineering and Management, 21(8), 1046-1060.

Arayici, Y., Ahmed, V., \& Aouad, G. (2006). A Requirements Engineering Framework for Integrated Systems Development for the Construction Industry. ITcon, 11, 35-55.

Aziz, Z., Anumba, C. J., \& Law, K. (2006). Using Context-Awareness and Web-Services to Enhance Construction Collaboration. In: 11th Joint International Conference On Computing And Decision Making In Civil And Building Engineering, 14-16 June, Montreal, Canada, Montreal, Canada, pp. 3010-3019.

Bacon, M. (2009). A data-centric, process-oriented model for effective collaborative working. In: Shen, G. Q., et al (Eds). Collaborative Construction Information Management, London, UK: Spon Press.

Baldwin, A. N., Austin, S. A., Poon, C., Shen, L., \& Wong, I. (2007). Reducing Waste in High Rise Residential Buildings by Information Modelling at the Design Stage. Surveying and Built Environment, 8(1), 51-62.

Buchanan, S. \& Gibb, F. (2007). The information audit: Role and scope. International Journal of Information Management, 27(3) 159-172.

Charoenngam, C., Coquinco, S. T., \& Hadikusumo, B. H. W. (2003). Web based application for managing change orders in construction projects. Construction Innovation, 3(4), 197-215.

Chassiakos, A. P. \& Sakellaropoulos, S. P. (2008). A web-based system for managing construction information, Advances in Engineering Software, 39(11), pp. 865-876.

Chen, D., Doumeingts, G., \& Vernadat, F. (2008). Architectures for enterprise integration and interoperability: Past, present and future. Computers in Industry, 59(7), 647-659.

Clarke, A. (1999). Evaluation Research: An Introduction to Principles, Methods and Practice. London: Sage Publications.

Connolly, T. M. \& Begg, C. E. (2010). Database Systems: A Practical Approach to Design, Implementation, and Management. 5th (ed.) London: Addison-Wesley.

Duerk, D. P. (1993). Architectural programming: Information Management for Design, New York; Chichester: John Wiley \& Sons.

East, E. W., \& and Nisbet, N. (2010). Analysis of life-cycle information exchange. In: Tizani, W., Proceedings of the International Conference in Computing in Civil and Building Engineering, 30 June-2 July, Nottingham, UK, Nottingham University Press, pp. 149-Paper 75.

Edum-Fotwe, F. T., \& Price, A. D. F. (2009). A social ontology for appraising sustainability of construction projects and developments. International Journal of Project Management, 27(4), 313322. 
Jallow et al 2017. "An enterprise architecture framework for electronic requirements information management.” International Journal of Information Management, 37(5), 455-472.

Erdogan, B., Anumba, C. J., Bouchlaghem, D. \& Nielsen, Y. (2008). Collaboration Environments for Construction: Implementation Case Studies, Journal of Management in Engineering, 24(4), pp. 234-244.

Fiksel, J., \& Dunkle, M. (1992). Principles of requirement management automation. In: Fiksel, J., Combined Proceedings of the 1990 and 1991 Leesburg Workshops on Reliability and Maintainability Computer-Aided Engineering in Concurrent Engineering, IEEE, 231-236.

Green, S., Newcombe, R., Fernie, S., \& Weller, S. (2004). Learning across Business Sectors: Knowledge Sharing between Aerospace and Construction, Reading: University of Reading.

Gray, D. E. (2009). Doing Research in the Real World. (2nd ed.). London: Sage.

Halbleib, H. (2004). Requirements Management. Information Systems Management, 21(1), 8-14.

Haug, A. (2012). The implementation of enterprise content management systems in SMEs. Journal of Enterprise Information Management, 25(4), 349-372.

Hullavarad, S., O’Hare, R. \& Roy, A. K. (2015). Enterprise Content Management solutions - Roadmap strategy and implementation challenges, International Journal of Information Management, 35(2), pp. 260-265.

Jallow, A. K., Demian, P., Baldwin, A. N., \& Anumba, C. J. (2008). Life cycle approach to requirements information management in construction Projects: state-of-the-art and future trends. In: Dainty, A., Proceedings of the 24th Annual ARCOM Conference, 1-3 September 2008, Cardiff, Wales, Association of Researchers in Construction Management, pp. 769-778.

Jallow, A.K., Demian, P., Baldwin, A. \& Anumba, C. (2010). Development of an Innovative Framework for Clients’ Requirements Information Management in Construction Projects, In: Anumba et al. (Ed) Proceedings of the 6th International Conference on Innovation in Architecture, Engineering and Construction (AEC), June 9-11, 2010, Penn State University, USA. 298-301.

Jallow, A.K.; Demian, P.; Baldwin, A., \& Anumba, C. (2014). An Empirical Study of the Complexities of Requirements Management in Construction Supply Chain. Engineering, Construction and Architectural Management, 21(5), 505-531.

Kagioglou, M. et al. (1998). A Generic Guide to the Design and Construction Process Protocol. UK: University of Salford.

Kamara, J. M., Anumba, C. J., \& Evbuomwan, N. F. O. (2002). Capturing client requirements in construction project, London: Thomas Telford Ltd.

Kamara, J. M., \& Anumba, C. J. (2000). Client Requirements Processing for Concurrent Life-Cycle Design and Construction. Concurrent Engineering: Research and Applications, 8(2), 74-88.

Kamara, J. M., Anumba, C. J., \& Evbuomwan, N. F. O. (2000). Process model for client requirements processing in construction. Business Process Management Journal, 6(3), 251-279.

Kiviniemi, A., Fischer, M., Bazjanac, V., \& Paulson, B. (2004). PREMISS - Requirements Management Interface to Building Product Models: Problem Definition and Research Issues, Stanford University: CIFE.

Kiviniemi, A. (2005). Requirements Management Interface to Building Product Models, Stanford University. (Unpublished PhD Thesis). Stanford:CIFE.

Lee, C. C., \& Egbu, C. (2008). Client requirements and project team knowledge in refurbishment projects, In: Smyth, H. and Pryke, S. (Eds). Collaborative Relationships in Construction: developing frameworks and networks, 59-77. Oxford: Wiley-Blackwell. 
Jallow et al 2017. "An enterprise architecture framework for electronic requirements information management.” International Journal of Information Management, 37(5), 455-472.

Laufer, A., Shapira, A., \& Telem, D. (2008). Communicating in Dynamic Conditions: How do On-Site Construction Project Managers Do It? Journal of Management in Engineering, 24(2), 75-86.

Maican, C., \& Lixandroiu, R. (2016). A system architecture based on open source enterprise content management systems for supporting educational institutions. International Journal of Information Management, 36(2), 207-214.

Meziane, F., \& Rezgui, Y. (2004). A document management methodology based on similarity contents. Information Sciences, 158, 15-36.

Minoli, D. (2008). Enterprise Architecture A to Z: Frameworks, Business Process Modeling, SOA, and Infrastructure Technology. NY: CRC Press.

Moses, S., El-Hamalawi, A. \& Hassan, T. M. (2008). "The practicalities of transferring data between project collaboration systems used by the construction industry", Automation in Construction, 17(7), pp. 824-830.

Oduguwa, P. A. (2006). Cost Impact Analysis for Requirements Management. (Unpublished PhD Thesis). Cranfield: Cranfield University.

OMG. (2011). Business Process Model and Notation (BPMN) Version 2.0. [Online]http://www.omg.org/spec/BPMN/2.0/ (Accessed October 2012).

Ozkaya, I., \& Akin, Ö. (2007). Tool support for computer-aided requirement traceability in architectural design: The case of DesignTrack. Automation in Construction, 16(5), 674-684.

Pearlson, K. E., \& Saunders, C. S. (2012). Managing \& Using Information Systems: A Strategic Approach. (5th ed.). New Jersey: Wiley.

Pena, W. M., \& Parshall, S. A. (2001). Problem Seeking: An Architectural Programming Primer. (4th ed.). New York, N.Y.; Chichester: John Wiley \& Sons.

Royal Institute of British Architects - RIBA. (2013). RIBA Plan of Work. London, UK: RIBA. [Online] http://www.ribaplanofwork.com/ (Accessed December 2014).

Ross, J. W., Weill, P., \& Robertson, D. (2006). Enterprise architecture as strategy: Creating a foundation for business execution. Boston: Harvard Business Review Press.

Schmidt, F. F. S., \& Souza, M. L. O. (2007). A New Procedure for Customizing Requirements Engineering Environment to Generate Requirements Reports Automatically. Warrendale, Pennsylvania, USA: SAE International.

Schooff, P. (2013). Processes, content and mobility: Strategies for successful combinations. ebizQ. [online] http://www.ebizq.net/topics/ecm/features/13449.html [Accessed February 2017].

Siemens. (2011). Introducing Teamcenter 8: Explore Teamcenter and discover your solution. [Online] http://www.plm.automation.siemens.com/en_gb/products/teamcenter/index.shtml [Accessed January 2011].

Sinha, V., Sengupta, B. and Chandra, S. (2006). Enabling Collaboration in Distributed Requirements Management. IEEE Software, 23(5), 52-61.

Soto-Acosta, P., Placer-Maruri, E., \& Perez-Gonzalez, D. (2016). A case analysis of a product lifecycle information management framework for SMEs. International Journal of Information Management, 36(2), 240-244.

The Open Group. (2006). TOGAF as an Enterprise Architecture Framework. [Online] http://pubs.opengroup.org/architecture/togaf8-doc/arch/ [Accessed: May 2015]. 
Jallow et al 2017. "An enterprise architecture framework for electronic requirements information management.” International Journal of Information Management, 37(5), 455-472.

Thomson, C. S., El-Haram, M. A., Hardcastle, C., \& Malcolm, R. (2008). Developing an urban sustainability assessment protocol reflecting the project lifecycle. In: Dainty, A. (Ed), Proceedings 24th Annual ARCOM Conference, 1-3 September, 1155-1164.

Tvete, B. (1999). Introducing efficient requirements management. In: Proceedings of the Tenth International Workshop on Database and Expert Systems Applications, 370-375.

Wilkinson, P. (2005). Construction Collaboration Technologies: The Extranet Evolution. Abingdon, Oxon, UK: Taylor and Francis.

Wong, F.W., \& Lam, P.T. (2011). Difficulties and Hindrances Facing End Users of Electronic Information Exchange Systems in Design and Construction. Journal of Management in Engineering, 27(1), 28-39.

Yu, A. T. W., Shen, G. Q. P. \& Chan, E. H. W. (2010). Managing employers' requirements in construction industry. Facilities, 28(7), 371-382.

Yu, A. T. W. \& Shen, G. Q. P. (2013). Problems and solutions of requirements management for construction projects under the traditional procurement systems, Facilities, 31(5/6), 223-237.

ZachmanInternational. (2008). “John Zachman’s Concise Definition of The Zachman Framework”. [Online] http://www.zachman.com/about-the-zachman-framework [Access: May 2015).

Zhao, Y., Tang, L.C.M., Darlington, M.J., Austin, S.A., \& Culley, S.J. (2008). High value information in engineering organisations. International Journal of Information Management, 28(4), 246-258. 